\title{
Crossmodal links between audition and touch in covert endogenous spatial attention
}

\author{
DONNA M. LLOYD \\ University of Oxford, Oxford, England \\ NATASHA MERAT \\ Unilever Research Port Sunlight Laboratories, Wirral, England \\ FRANCIS MCGLONE \\ Unilever Research Port Sunlight Laboratories, Wirral, England \\ and University of Wales, Bangor, Wales \\ and \\ CHARLES SPENCE \\ University of Oxford, Oxford, England
}

\begin{abstract}
We report three experiments designed to investigate the nature of any crossmodal links between audition and touch in sustained endogenous covert spatial attention, using the orthogonal spatial cuing paradigm. Participants discriminated the elevation (up vs. down) of auditory and tactile targets presented to either the left or the right of fixation. In Experiment 1, targets were expected on a particular side in just one modality; the results demonstrated that the participants could spatially shift their attention independently in both audition and touch. Experiment 2 demonstrated that when the participants were informed that targets were more likely to be on one side for both modalities, elevationjudgments were faster on that side in both audition and touch. The participants were also able to "split" their auditory and tactile attention, albeit at some cost, when targets in the two modalities were expected on opposite sides. Similar results were also reported in Experiment 3 when participants adopted a crossedhands posture, thus revealing that crossmodal links in audiotactile attention operate on a representation of space that is updated following posture change. These results are discussed in relation to previous findings regarding crossmodal links in audiovisual and visuotactile covert spatial attentional orienting.
\end{abstract}

There has been a rapid growth of interest in issues related to crossmodal selective attention and multisensory integration in the last few years (see Calvert, Brammer \& Iversen, 1998; Driver \& Spence, 1998b, 1998c; Macaluso, Frith, \& Driver, 2001; Spence, 2001; Spence \& Driver, in press, for reviews). Converging evidence from behavioral studies in both normals and clinical patients (e.g., di Pellegrino, Làdavas, \& Farné, 1997; Mattingley, Driver, Beschin, \& Robertson, 1997; Spence \& Driver, 1997b), from electrophysiologicalstudies (e.g., Eimer \& Schröger, 1998; Kennett, Eimer, Spence, \& Driver, 2001; McDonald \& Ward, 2000a; Teder-Sälejärvi, Münte, Sperlich, \& Hillyard, 1999) and from neurophysiological research in

\footnotetext{
The authors thank Unilever Research and Christopher Dancer of the Pain Research Institute, Liverpool, for technical support. We also thank John McDonald, Brigitte Roeder, Lawrence Ward, and an anonymous reviewer for their very detailed and helpful comments on earlier drafts of this manuscript. D.M.L. is affiliated with both the Department of Psychology and the FMRIB Centre of Oxford University. Correspondence concerning this article should be addressed to C. Spence, Department of Experimental Psychology, University of Oxford, South Parks Road, Oxford OX13UD, England (e-mail: charles.spence@psy.ox.ac.uk).
}

animals (e.g., Graziano \& Gross, 1996, 1998; Stein \& Meredith, 1993) all demonstrate extensive crossmodal links in the control of attention and information processing. However, the majority of behavioral studies have focused on links between either audition and vision (e.g., Driver \& Spence, 1994; McDonald \& Ward, 2000b; Mondor \& Amirault, 1998; Spence \& Driver, 1996, 1997a; Ward, 1994) or vision and touch (e.g., Butter, Butchel, \& Santucci, 1989; Pavani, Spence, \& Driver, 2000; Spence, Pavani, \& Driver, 2000; Spence, Shore, \& Klein, 2001). To date, only relatively few studies have attempted to investigate possible crossmodal links in attention (and/or multisensory integration effects) between audition and touch (Caclin, Soto-Faraco, Kingstone, \& Spence, 2002; Eimer, Van Velzen, \& Driver, 2002; Guest, Catmur, Lloyd, \& Spence, 2002; Hötting, Rösler, \& Röder, 2002; Jousmäki \& Hari, 1998; Làdavas, Pavani, \& Farnè, 2001; Merat, Spence, Lloyd, Withington, \& McGlone, 1999; Spence, Nicholls, Gillespie, \& Driver, 1998).

Spence et al. (1998) reported a series of experiments investigating any crossmodal links in covert spatial attention between touch, audition, and vision in which spatially nonpredictive cues were presented to the left or right 
of fixation, shortly before (150-300 msec) an imperative target signal (again presented to either the left or the right) requiring a speeded discrimination response. Continuous versus pulsed discrimination responses to tactile targets were more rapid and accurate when they were preceded by an auditory or visual cue on the same side. Similarly, auditory and visual up-down elevation discrimination responses were facilitated by a preceding tactile cue. These results suggest the existence of symmetrical crossmodal links in attention between audition and touch, and also between touch and vision (where support for the existence of a crossmodal link in attention comes from behavioral evidence demonstrating that a shift of attention in one sensory modality can elicit an involuntary shift of attention in another sensory modality). Although the nature of any crossmodal links between audition and vision affecting behavioral responses has been somewhat controversial (e.g., see Driver \& Spence, 1998a; McDonald \& Ward, 2000b; Spence \& Driver, 1997a; Ward, 1994; Ward, McDonald, \& Golestani, 1998; Ward, McDonald, \& Lin, 2000), the weight of empirical evidence now supports the view that there are actually symmetrical links between audition and vision as well (e.g., McDonald, Teder-Sälejärvi, Heraldez, \& Hillyard, 2001; McDonald, Teder-Sälejärvi, \& Hillyard, 2000; see Spence, 2001, for a recent review). Taken together, these results therefore suggest that the peripheral presentation of a spatially nonpredictive auditory, visual, or tactile cue elicits a brief exogenous shift of a supramodal attentional spotlight that will facilitate the processing of any sensory stimulus (no matter what its modality) subsequently presented at or near the cued location (Spence, 2001).

The results of these peripheral-cuing studies refer specifically to crossmodal links in purely exogenous (or stimulus-driven) attentional orienting, because the peripheral cues were uninformative with regard to the likely location of the target. However, a distinction has been made between exogenous orienting and the endogenous (or voluntary) orienting induced by advance knowledge of where a target is most likely to occur (Posner, 1978). Several differences between these two forms of attention have been reported both in terms of their effect on behavior (e.g., Briand, 1998; Klein \& Shore, 2000; Spence \& Driver, 1994, 1996, 1997a), and in terms of their underlying neural substrates (e.g., Butter, 1987; Làdavas, 1993; Rafal, Henik, \& Smith, 1991). For example, exogenous orienting is not disrupted by a secondary verbal memory task that disrupts endogenous orienting (Jonides, 1981), and it is also less subject to interruption by subsequent visual events than is endogenous orienting (Müller \& Rabbitt, 1989). Given these differences, it is important, at least at first, to examine separately the nature of any crossmodal links in exogenous and endogenous spatial orienting. Here, we examined the nature of crossmodal links between audition and touch specifically for the case of endogenous covert spatial orienting.

A number of behavioral and event-related potential (ERP) studies have demonstrated extensive crossmodal links in the control of endogenous spatial attention be- tween audition and vision (e.g., Driver \& Spence, 1994; Eimer \& Schröger, 1998; Hillyard, Simpson, Woods, Van Voorhis, \& Münte, 1984; Spence \& Driver, 1996; Spence, Ranson, \& Driver, 2000; Teder-Sälejärvi et al., 1999). These studies have shown that shifting attention in one modality typically leads to a concomitant shift of attention in the other modality in the same direction (albeit at a reduced level). However, it has also been shown that people can, to some extent, direct auditory and visual attention in different directions simultaneously, at least under certain conditions (Driver \& Spence, 1994; Eimer, 1999; Spence \& Driver, 1996; Spence, Ranson, \& Driver, 2000). Similar crossmodal links in endogenous orienting have also been demonstrated between vision and touch (Eimer \& Driver, 2000; Spence, Pavani, \& Driver, 2000; but see also Posner, Nissen, \& Ogden, 1978). These results, together with the extensive neurophysiological and electrophysiological evidence of widespread integration of auditory and tactile information in the brain (see, e.g., Di, Brett, \& Barth, 1994; Foxe et al., 2000; Graziano, Hu, \& Gross, 1997; Meredith, Wallace, \& Stein, 1992; Stein \& Meredith, 1993), suggest that any audiotactile links in endogenous spatial attention may be similar to those already reported between audition and vision and between vision and touch. However, as the recent controversy surrounding the nature of crossmodal links in exogenous orienting between audition and vision makes clear (see, e.g., McDonald \& Ward, 2000b; Spence \& Driver, 1997a; Ward, 1994), it is also possible that different crossmodal links may subserve different pairs of sensory modalities, depending on their particular functional/evolutionary role in guiding our behavior. Indeed, given the literature on visual dominance (e.g., Posner, Nissen, \& Klein, 1976; Spence, Shore, \& Klein, 2001), which indicates that vision has a more central role in information processing and attention than either audition or touch (see also Eimer, in press), one might predict weaker crossmodal links between audition and touch than have been reported previously between vision and the other sensory modalities (see also the General Discussion section on this point).

The following experiments were designed to examine the nature of any crossmodal links between audition and touch in the sustained control of endogenous covert spatial attention. We examined whether participants can sustain their spatial attention at a particular location in one modality and not in the other (Experiment 1) and whether they can shift attention in both modalities together or direct them in different directions (Experiment 2). Finally, we examined what happens to crossmodal links in endogenous spatial attention when the hands are crossed over the body midline (Experiment 3 ), to investigate whether crossmodal links between auditory and tactile attention are updated when posture changes.

\section{EXPERIMENT 1}

Experiment 1 was designed to examine whether there is any natural predisposition for endogenous spatial attention 
to shift together in audition and touch, using the up-down discrimination task (a tactile analog of the orthogonalcuing paradigm introduced by Spence \& Driver, 1994, $1996,1997 b)$. In this task, participants hold a foam cube between the thumb and the forefinger of each hand (see Figure 1 for a schematic view of the experimental set-up seen from a raised position behind the participant's cartooned body). One tactile vibrator is positioned under each thumb and another under each forefinger.

For half of the experiment (Experiment 1A), the participants were instructed to direct just their tactile attention (the primary modality) to one or the other side for each block of trials and to leave their auditory attention (the less common, secondary modality) spatially diffuse. The event probabilities were manipulated to encourage this strategy strongly. For the other half of the experiment (Experiment 1B), the instructions and probabilities were reversed: The participants were instructed to direct their auditory attention (now primary) to one or the other side and to leave their tactile attention (now secondary) spatially diffuse, with the event probabilities being changed accordingly. In order to encourage the participants to follow the instructed strategy, $73 \%$ of all targets appeared in the currently primary modality, and seven of every eight targets in this more common modality appeared on the expected side. The rarer targets (only $27 \%$ of the total) in the secondary modality were actually more likely to appear on the opposite side, at a ratio of $2: 1$. The participants therefore had a very strong spatial expectancy about the likely target side within the primary modality. They also had a strong motivation to attend to the highly likely side within just the primary modality, but no strategic reason for attending to that side in the secondary modality (as event probabilities were weighted 2:1 against doing so).

On the basis of previous work in the audiovisual domain (Spence \& Driver, 1996), it was anticipated that the participants would be able to direct their attention in the

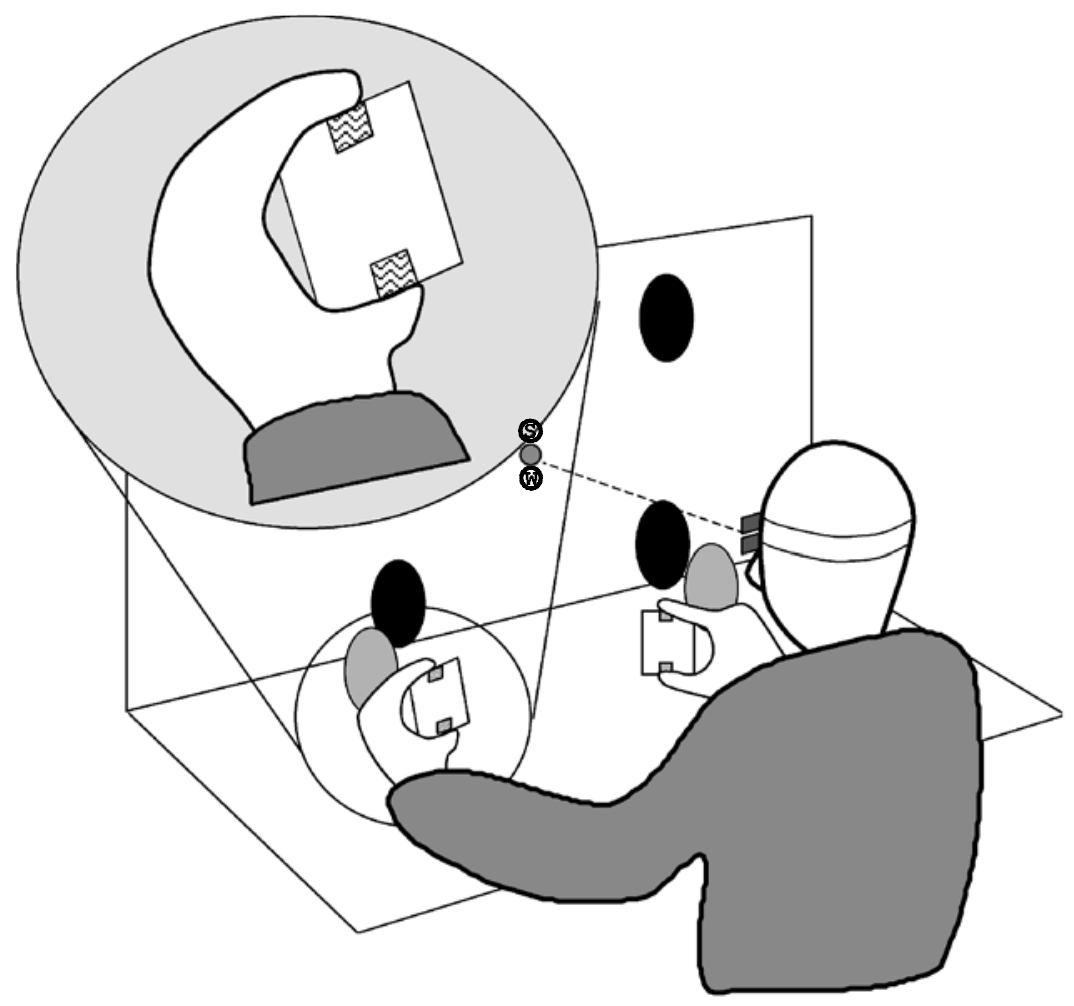

O Fixation Light

Auditory Loudspeakers

Tactile Stimulators

\section{Masking Loudspeakers (๑) Feedback Lights}

Figure 1. Schematic view of the apparatus and the participant's position in Experiment 1 . The enlarged inset shows the two vibrotactile stimulators inset into each of the foam cubes that the participant gripped to provide potential vibrotactile targets on either side. 
expected direction for the primary modality. A more interesting question was what would happen to the spatial distribution of attention in the secondary modality. According to the modality-specific attentional resource account (Duncan, Martens, \& Ward, 1997; Robin \& Rizzo, 1989; Wickens, 1984, 1992), people should have no difficulty in spatially directing attention in just one modality while leaving attention in the other modality diffuse (or, indeed, directing attention in the secondary modality to the opposite side, where targets in that modality were twice as likely). By contrast, if there are crossmodal links in endogenous spatial attention between audition and touch, then any shift of attention toward the expected side in the primary modality should be accompanied by a concomitant shift of attention in the same direction in the secondary modality. This should occur even though events in the secondary modality are more likely elsewhere.

\section{Method}

Participants. Fourteen participants ( 7 men and 7 women) took part in this experiment, and all were naive to its purpose. Their mean age was 39 years, with a range of $25-55$ years, and all were right-handed by self-report. All reported normal hearing and touch. The experiment took approximately $55 \mathrm{~min}$ to complete.

Apparatus and Materials. A red LED placed $30 \mathrm{~cm}$ in front of the participants at eye level served as the central visual fixation point. The participants held sponge cubes between the foref ingers and thumbs of both hands, which were placed $50 \mathrm{~cm}$ apart (see Figure 1). Four Oticon-A (100-ohm) bone-conduction vibrators with vibrating surfaces, measuring $1.6 \mathrm{~cm} \times 2.4 \mathrm{~cm}$, were used to present the vibrotactile targets and were mechanically isolated within the foam cubes (both rise and fall times for the vibrators were approximately $20 \mathrm{msec}$ ). The lower rear edge of each of the foam cubes was attached to the tabletop with Velcro in all of the experiments to ensure that the cubes remained in the correct position with respect to each other and to the participant, no matter what posture the participant adopted. The Velcroing of the cubes to the tabletop also ensured that the upper stimulators remained above the lower stimulators (that is, the participants could not rotate the cubes such that, for example, the thumb and forefinger became horizontally separated). The vibrators were placed directly on the thumb and forefinger pads of each hand and were separated vertically by a distance of $7.5 \mathrm{~cm}$. The vibrators were situated $45 \mathrm{deg}$ below fixation and 32.4 deg to either side of midline. Tactile stimuli could be presented from any one of the four vibrators, which were driven by a $200-\mathrm{Hz}$ sine wave fed through a Realistic SA-155 amplifier. The vibrotactile stimuli were presented well above threshold and required an elevation discrimination of $10.8 \mathrm{deg}$ vertically. The tactile target stimuli consisted of three successive 50 -msec bursts of stimulation separated by 50 -msec empty intervals.

Preliminary testing on 6 participants (50 trials per participant) conducted before the main experiments revealed that they could not discriminate the location of the vibrotactile stimulus at significantly above chance level when responding solely on the basis of any sounds made by the vibrotactile stimulators (i.e., when their hands were not placed in contact with the vibrotactile stimulators). During the course of the actual experiment, any participants who reported that they thought they could perform the task on the basis of the sound made by the vibrators were encouraged to perform a few trials without their hands on the foam cubes. In all of the relatively few cases in which this happened, the participants concerned were unable to perform the "tactile" elevation discrimination task accurately by sound alone, satisfying both the participant and the ex- perimenter that they were really basing their elevation judgments on the vibrotactile cues.

Auditory targets could be presented from any one of the four target loudspeaker cones, which were placed $60 \mathrm{~cm}$ apart horizontally and $45 \mathrm{~cm}$ apart vertically (see Figure 1 ). The auditory task required an elevation discrimination of 49.2 deg vertically. The auditory targets consisted of three successive $50-\mathrm{msec}$ bursts of white noise presented at approximately $95 \mathrm{~dB}(\mathrm{~A})$, as measured from the participant's ear position, and separated by $50-\mathrm{msec}$ silent intervals. Throughout the experiment white noise was presented at $88 \mathrm{~dB}(\mathrm{~A})$ from two loudspeaker cones situated behind the tactile stimulators to mask any sound made by the operation of the vibrators. It is worth noting that, because of the high-background white noise levels required to ensure that the participants were unable to discriminate the location of the vibrotactile targets by sound alone, the signal-to-noise ratio for the auditory targets (i.e., $7 \mathrm{~dB}$ ) was lower than that for the vibrotactile targets, and also much lower than the signal-to-noise ratio for auditory, visual, and tactile targets in our previous endogenous studies of spatial attention (Spence \& Driver, 1996; Spence, Pavani, \& Driver, 2000). For comparison, if we assume a background noise level of around $35 \mathrm{~dB}$ in the soundproof booth in which Spence and Driver (1996) conducted their experiments on audiovisual links in endogenous spatial attention, then the $85-\mathrm{dB}$ auditory targets they used would have been presented at a signal-to-noise ratio of approximately $50 \mathrm{~dB}$.

The participants made elevation discrimination responses regarding whether a target came from one of the upper locations (by their forefingers for tactile targets and from the upper loudspeakers for auditory targets) or from one of the lower locations (by their thumbs for tactile targets and from the lower loudspeakers for auditory targets). This decision was made regardless of the laterality or modality of the target. It should be noted here that one potential limitation of the orthogonal cuing task, especially when used to assess auditory perception, is that many people typically show poor auditory elevation discrimination ability, thus requiring the target loudspeakers to be separated by a relatively large elevation difference. In the present study, in which we investigated links between audition and touch, this led to a difference in possible target elevation for the two modalities. In the General Discussion section, we discuss whether this difference may have affected the pattern of results observed. Responses were made via footpedals placed below the table. One pedal was placed below the toe and the other pedal below the heel of the participant's right foot. Upper targets were indicated by raising the toe briefly, and lower targets by raising the heel briefly.

Design and Procedure. The participants were informed that targets in the primary modality (touch in Experiment 1A, audition in Experiment 1B) would be more common overall, and were very likely to appear on the side specified verbally at the start of each block of trials. This side varied between blocks, so that each modality was equally likely to be more probable toward the left or toward the right of the participant overall, both when it served as the primary modality and when it served as the secondary modality.

The participants were told that the much rarer targets in the secondary modality (audition in Experiment 1A, touch in Experiment $1 \mathrm{~B}$ ) were slightly more common on the side opposite that which was likely for the primary modality. Note that the weighting of target stimuli in the secondary modality was somewhat different from that reported in recent electrophysiological studies of audiotactile links in endogenous spatial attention (see, e.g., Eimer et al., 2002; Hötting et al., 2002), and this may help to account for the differences found between these studies (see the Discussion section of Experiment 1 on this point). At the beginning of every block of trials in Experiment 1A, the participants in our study were instructed to direct their tactile attention to the expected side for tactile targets and to leave their auditory attention spatially diffuse (again, it was emphasized that there was no reason to direct auditory attention to the same side as touch, since the rarer auditory targets were actually 
twice as likely on the opposite side). This instruction was reversed in Experiment 1B, in which the participants were instructed to keep their tactile attention as spatially diffuse as possible and to direct their auditory attention to the expected side for auditory targets. In each part of the experiment, the participants completed two blocks of 48 practice trials, followed by four blocks of 88 test trials.

Half of the participants completed Experiment 1A before Experiment $1 \mathrm{~B}$, whereas the remainder completed Experiment $1 \mathrm{~B}$ first. The horizontal position of the right eyes of 7 of the participants was monitored by means of a Skalar infrared-light eye tracker (Model 6500), to ensure that any spatial expectancy effects could be attributed to the covert, rather than to the overt, orienting of attention. The eye-movement monitor was calibrated to provide a signal to the computer whenever an eye movement of 2 deg or more was detected in the period between target onset and the initiation of a footpedal response. (This was the smallest signal that could be consistently detected across participants with the apparatus, but note that the peripheral targets were located at an eccentricity of more than $30 \mathrm{deg}$ from the central fixation point.) The monitor was recalibrated to confirm true straight-ahead at the beginning of every block of trials and also during a block if fixation appeared to drift from the calibrated center point. Trials in which potential eye movements were detected (note that blinks sometimes resulted in signals that were indistinguishable from actual eye-movement signals) were automatically excluded from the analyzed data.

Each trial was initiated by the onset of the fixation light and was followed, at an SOA that varied randomly between 500 and $800 \mathrm{msec}$, by the onset of a target. After the participant had made his or her response and any feedback had been presented, there was a delay of $1,000-1,300 \mathrm{msec}$ before the fixation light came on again to signal the start of the next trial. The trial was terminated if no response was made within 1,500 msec of target onset. Error feedback was provided if the participant made an incorrect response (a green LED situated below the fixation light flickered for $780 \mathrm{msec}$ ) or if the response made was too slow (longer than $1,500 \mathrm{msec}$; a green LED above the fixation light flickered for $780 \mathrm{msec}$ ).

\section{Results}

Fewer than $15 \%$ of the trials were removed due to excessive eye movements (or blink artifacts) for those participants whose eye position was monitored, and $1.4 \%$ were removed due to the absence of response. The interparticipant mean reaction times (RTs) after these exclusions, together with the corresponding error rates for all trials, are shown in Table 1 as a function of primary modality (i.e., whether touch or audition was the more probable target modality-Experiments $1 \mathrm{~A}$ and 1B, respectively), target modality, and target side, as a function of whether or not eye position was monitored. The mean spatial expectancy effects are also summarized in Figure 2, pooled across the eye-monitoring factor. Miller (1988) has demonstrated that because of the positive skew present in the majority of RT distributions, sample medians tend to overestimate population medians in inverse relationship to sample size. Therefore, given that the different cue conditions had different probabilities of occurrence in the present study, with valid trials being more likely overall, mean rather than median RTs were computed for each participant.

The data were analyzed using a mixed analysis of variance (ANOVA), with the between-participants factor of whether or not eye position was monitored [eye monitoring (2)] and the three within-participants factors of spatial expectancy (2: target presented on the side that was expected vs. on the unexpected side for the primary modality), target modality (2: auditory vs. touch), and primary modality (2: auditory vs. touch). We also performed additional analyses on the data from this and subsequent experiments to examine whether there were any differences between the attentional effects reported for upper and lower target positions. Although some differences were found between upper and lower target positions, none of these effects alter the interpretations of the major results described in the text. These additional data analyses are reported in the Appendix. Note that all of the ANOVAs reported in this study were based on the general linear model, using SPSS Version 11.0. All of

Table 1

Mean Reaction Times (RTs, in Milliseconds), Standard Errors (SEs), Percentages of Errors (\%), and Mean Expectancy Effects for Auditory and Tactile Targets in Experiment 1 as a Function of Eye Monitoring, Primary Modality, and Target Side

\begin{tabular}{|c|c|c|c|c|c|c|c|c|c|}
\hline \multirow{3}{*}{$\begin{array}{l}\text { Primary } \\
\text { Modality }\end{array}$} & \multirow{3}{*}{$\begin{array}{l}\text { Target } \\
\text { Modality }\end{array}$} & \multicolumn{6}{|c|}{ Target Side } & \multirow{2}{*}{\multicolumn{2}{|c|}{$\begin{array}{c}\text { Mean Expectancy } \\
\text { Effect }\end{array}$}} \\
\hline & & \multicolumn{3}{|c|}{ Expected } & \multicolumn{3}{|c|}{ Unexpected } & & \\
\hline & & $\overline{\mathrm{RT}}$ & $S E$ & $\%$ & RT & $S E$ & $\%$ & RT & $\%$ \\
\hline \multicolumn{10}{|c|}{ Eye Movement Not Monitored $(n=7)$} \\
\hline \multirow[t]{2}{*}{ Auditory primary } & Auditory & 703 & 37 & 7.1 & 806 & 36 & 13.4 & $103 *$ & 6.3 \\
\hline & Tactile & 666 & 41 & 3.1 & 668 & 40 & 3.3 & 2 & 0.2 \\
\hline \multirow[t]{2}{*}{ Touch primary } & Tactile & 568 & 29 & 2.4 & 646 & 30 & 1.6 & $78^{*}$ & $-0.8 *$ \\
\hline & Auditory & 815 & 43 & 17.4 & 802 & 39 & 14.4 & $-13^{*}$ & $-3.0 *$ \\
\hline \multicolumn{10}{|c|}{ Eye Movement Monitored $(n=7) \%$} \\
\hline \multirow[t]{2}{*}{ Auditory primary } & Auditory & 578 & 38 & 7.7 & 660 & 47 & 10.5 & $82 *$ & 2.8 \\
\hline & Tactile & 627 & 28 & 8.5 & 615 & 25 & 7.5 & -12 & -1.0 \\
\hline \multirow[t]{2}{*}{ Touch primary } & Tactile & 504 & 18 & 3.0 & 561 & 23 & 4.0 & $57 *$ & 1.0 \\
\hline & Auditory & 681 & 54 & 21.0 & 671 & 53 & 22.6 & -10 & 1.6 \\
\hline
\end{tabular}

Note- ${ }^{*} p<.00625$. Target side refers to whether the target appeared on the side that was expected in the primary modality only. This strict criterion for significance reflects our use of Bonferroni $t$-test pairwise comparisons to correct for possible familywise error rates when multiple planned comparisons are performed. 


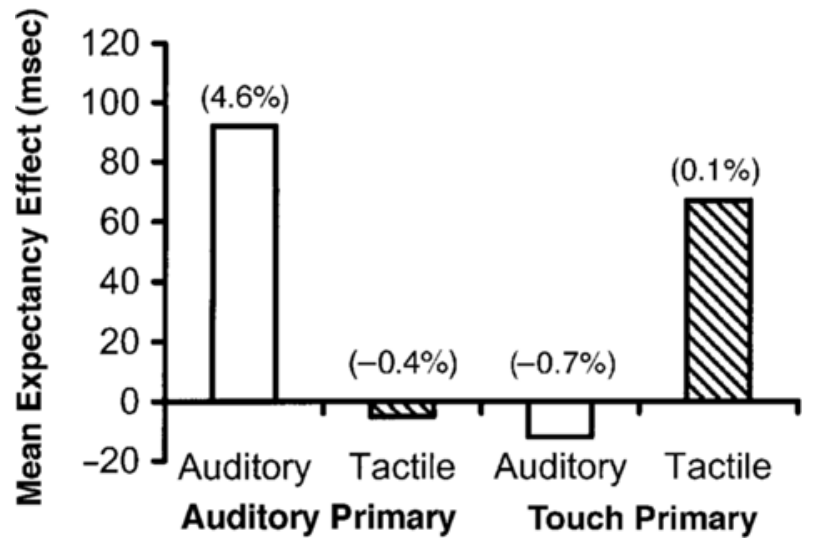

Figure 2. Mean spatial expectancy effects on reaction time, averaged across the eye-monitoring factor, for Experiments $1 \mathrm{~A}$ (touch primary) and $1 \mathrm{~B}$ (auditory primary). White bars show effects for auditory targets, striped bars those for tactile targets. Average expectancy effects in error rates are shown in parentheses.

the data were checked for heteroskedasticity and sphericity, and no corrections were required. Analysis of the RT data revealed a main effect of spatial expectancy $[F(1,12)=$ $34.4, p<.001]$ caused by the participants' responding more rapidly to targets presented on the expected side $(M=589 \mathrm{msec})$ as opposed to those appearing on the unexpected side $(M=668 \mathrm{msec})$ overall. This spatial expectancy effect was significantly larger in the primary modality (mean unexpected - expected side difference of $80 \mathrm{msec}, p<.001$ by $t$ test pairwise comparison) than in the secondary modality $(M=-8 \mathrm{msec}$, n.s. $)$, resulting in an interaction between spatial expectancy and primary modality $[F(1,12)=69.0, p<.001]$. The participants responded more rapidly to targets when they occurred in the primary modality $(M=628 \mathrm{msec})$ than in the less common secondary modality $(M=693 \mathrm{msec})$, resulting in a main effect of primary modality $[F(1,12)=20.8, p<$ $.001]$. The participants responded more rapidly to tactile targets $(M=607 \mathrm{msec})$ than to auditory targets $(M=$ $715 \mathrm{msec}$ ) overall, resulting in a main effect of target modality $[F(1,12)=21.0, p=.001]$. Finally, there was a main effect of eye monitoring $[F(1,12)=5.4, p=.04]$ caused by the unmonitored participants' responding more slowly than the eye-monitored participants $(M=$ $709 \mathrm{msec}$ vs. $612 \mathrm{msec}$, respectively), but, crucially, there were no interactions between eye monitoring and any of the other factors [for spatial expectancy $\times$ eye monitoring, $F(1,12)=1.2, p=.30$; for target modality $\times$ eye monitoring, $F(1,12)=2.5, p=.14 ; F<1$ for all other terms involving the eye-monitoring factor], showing that overt orienting cannot account for the expectancy effects reported here. None of the other terms in the RT analysis reached significance [for target modality $\times$ spatial expectancy, $F(1,12)=1.0, p=.33$; for spatial expectancy $\times$ primary modality $\times$ target modality, $F(1,12)=2.2$, $p=.16 ; F<1$ for all other terms].
A similar ANOVA on the accuracy data revealed a main effect of primary modality $[F(1,12)=6.6, p<.05]$, with participants making fewer errors to targets in the primary modality $(M=6.2 \%)$ than to targets in the secondary modality $(M=12.2 \%)$. There was also a main effect of target modality $[F(1,12)=16.1, p=.002]$ caused by the participants' making more errors in response to auditory targets $(M=14.3 \%)$ than in response to tactile targets $(M=4.2 \%)$ overall. The participants also made more errors in response to targets presented on the side that was unexpected for the primary modality $(M=$ $7.4 \%)$ than on the expected side $(M=5.1 \%)$, resulting in a significant interaction between primary modality and spatial expectancy $[F(1,12)=5.2, p=.04]$. This result rules out a potential criterion-shifting account for these RT effects (see, e.g., Duncan, 1980; Spence \& Driver, $1997 \mathrm{c})$. There was no main effect of eye monitoring $[F(1,12)=0.4$, n.s. $]$ and no interaction between eye monitoring and any of the other factors [for primary modality $\times$ eye monitoring, $F(1,12)=1.2, p=.30$; for eye monitoring $\times$ target modality $\times$ spatial expectancy $\times$ primary modality, $F(1,12)=2.8, p=.12 ; F<1$ for all other terms involving the eye-monitoring factor]. None of the other error terms in the analysis of the error data reached significance [for spatial expectancy, $F(1,12)=$ $1.1, p=.31$; for target modality $\times$ spatial expectancy, $F(1,12)=1.5, p=.24$; for primary modality $\times$ target modality, $F(1,12)=2.4, p=.15$; for target modality $\times$ spatial expectancy $\times$ primary modality, $F(1,12)=2.1$, $p=.18 ; F<1$ for all other terms].

\section{Discussion}

In Experiment 1, we examined whether there was any natural tendency for endogenous spatial attention to shift together in audition and touch. The results clearly demonstrate that when participants have a strong spatial expectancy about target location in one modality (i.e., the more common primary modality), their endogenous spatial attention shifted to that side only within the primary modality, and not within the secondary modality (see Figure 2). That is, there was no evidence that attention in the secondary modality shifted in the same direction as that of the primary modality. If anything, there was a slight trend in the opposite direction - that is, for attention in the secondary modality to shift in the direction opposite that of the primary modality (i.e., to the side on which targets in the secondary modality were actually more likely to occur). ${ }^{1}$

These results would appear to demonstrate that there is more independence between endogenous auditory and tactile spatial attention than has been shown previously for crossmodal links in either audiovisual (Spence \& Driver, 1996) or visuotactile (Spence, Pavani, \& Driver, 2000) attention, in which a shift in one modality has been shown to lead to a concomitant shift of attention in the other modality in the same direction. In fact, the results of Experiment 1 suggest that people are able to se- 
lectively direct (and sustain) their spatial auditory or tactile attention to one side or the other with no effect on the spatial distribution of attention in the other modality. These results are inconsistent with a purely supramodal account of crossmodal links in attention (see, e.g., Farah, Wong, Monheit, \& Morrow, 1989; Robin \& Rizzo, 1989). According to the supramodal account, the processing of all sensory information at an attended location should be facilitated, and not just for the primary modality, as is shown here. Instead, our results are more consistent with the modality-specific resource account of attention, according to which attention can be directed independently for each modality (see, e.g., Bushara et al., 1999; Duncan et al., 1997; Wickens, 1980, 1984, 1992).

At first glance, our results would also appear to be inconsistent with the results of Hötting et al.'s (2002) recent ERP study of crossmodal links in sustained endogenous spatial attention between audition and touch. The participants in their study were presented with streams of auditory and tactile stimuli that came equiprobably from either side of fixation in either modality. The participants were instructed to attend to one side in just one modality on a block-by-block basis, and to detect the infrequent deviant target stimuli presented on that side in one modality and ignore all other standard (more frequent) and deviant stimuli presented from either side in the other modality. Analysis of the ERP data revealed that a sustained endogenous shift of just auditory attention to one side resulted in a significant enhancement of just both early and late auditory ERPs, and that a shift of tactile spatial attention resulted in a significant enhancement of both early and late somatosensory ERPs to stimuli in the attended modality on the attended (in comparison with the unattended) side. More importantly, their study also found smaller but still significant enhancements of early ERPs in response to stimuli presented in the "unattended" modality, thus providing electrophysiological evidence for the existence of crossmodal links in endogenous spatial attention between audition and touch. Similar evidence for crossmodal links in endogenous spatial attention from touch to audition have also been reported by Eimer and colleagues using both blocked-cuing (Eimer et al., 2002) and trial-by-trial cuing designs (Eimer, Cockburn, Smedley, \& Driver, 2001).

It is important to note, however, that the participants in Hötting et al.'s (2002) study had no strategic reason not to shift their attention in the unattended modality in the same direction as for the attended modality, since no response was ever made to any of the stimuli in the "unattended" modality. What's more, the stimuli in Hötting et al.'s study were equally likely to be presented from either side. This contrasts with the procedure of the present study, in which targets in the secondary modality were actually weighted so as to be more likely to appear on the opposite side as targets in the primary modality.
Consequently, our participants had a strategic reason not to shift their attention in the secondary modality in the direction in which their attention shifted in the primary modality. They were also verbally instructed to try not to shift their spatial attention in the secondary modality. Therefore, whereas Hötting et al.'s results may demonstrate the existence of some crossmodal links in spatial attention between audition and touch, they do not distinguish whether such links are obligatory or merely optional (see Eimer, in press, and the General Discussion section on this point). Moreover, in another recent ERP study, Eimer et al. (2002) reported that people can disengage their tactile attention when touch is completely irrelevant to the task and they are required only to direct their auditory attention to one side or another. Therefore, whereas there is some disagreement between the ERP studies reported by Hötting et al. and Eimer et al. (2002), the results of the latter are entirely consistent with the behavioral results reported in the present experiment. The results of Experiment 1 therefore support the view that when it is detrimental to performance (i.e., when the stimulus probabilities/experimenter's instructions are weighted against it), people can prevent a shift of attention in the secondary modality in the direction of a shift in the primary modality. Our results also suggest that the crossmodal links in spatial attention between audition and touch reported in Hötting et al.'s ERP study are, in some sense, optional, in that attention to one modality can be directed to a particular location in space, without this having any necessary consequences for the spatial distribution of attention in the other modality (see also Eimer et al., 2002, on this point). It should also be noted that the present study provides the first robust data regarding the behavioral consequences of such crossmodal links in attention, as the previous studies focused primarily on just electrophysiological measures of perception. We further assess the nature of the links in sustained endogenous spatial attention between these two modalities in the following experiments.

\section{EXPERIMENT 2}

In Experiment 2, we examined whether people could separate their auditory and tactile endogenous spatial attention when equally strong but opposite spatial expectancies were applied within each modality. This is a stronger test of the modality-specific nature of attentional resources than that presented in Experiment 1 (or in the studies of Eimer et al., 2001; Eimer et al., 2002; and Hötting et al., 2002). The experimental paradigm adopted was similar to that used by Spence and Driver (1996, Experiment 7) in their audiovisual studies. The likely target side was again blocked for each modality, as in Experiment 1, except that the targets were now equally likely to appear in either modality, rather than one modality being primary. In some blocks of trials, both auditory and tactile targets were more likely ( $83 \%$ of all trials) to be on a common 
side-for example, on the left. In other same-side blocks, both were more likely to be on the right, and in either case the participants were verbally informed of these probabilities in advance (as in Experiment 1). By comparing performance for targets on the likely versus the unlikely side within these same-side blocks, we were able to examine whether judgments were better on the expected side for each modality, as if people could shift and sustain attention independently to the same location in both modalities (see, e.g., Posner et al., 1978).

On additional blocks of trials, tactile and auditory targets were both more likely $(83 \%$ of all trials for each modality) to be on opposite sides (i.e., throughout a block tactile targets were more commonly on the left and auditory targets on the right, or vice versa). Comparing performance on expected and unexpected sides within each modality for these different-sides blocks provides a measure of whether participants can spatially separate endogenous auditory and tactile attention. Moreover, comparing the size of any spatial effects in the differentsides blocks to those reported for the same-side blocks provides a measure of whether attempting to endogenously "split" auditory and tactile spatial attention reduces efficiency. The modality-specific resource account predicts that there should be no reduction in efficiency in the different-side blocks in comparison with the sameside blocks, because if there are independent attentional systems for each modality, then it should be no more difficult to direct them to different sides, than to the same side of space (cf. Eimer, 1999).

\section{Method}

Participants. Forty-two participants took part in this experiment. Their ages ranged from 21 to 47 years, with a mean of 32 years, and all were right-handed by self-report. All were naive as to the purpose of the experiment, and none had taken part in the previous experiment. The experiment took approximately $60 \mathrm{~min}$ to complete. All the participants reported normal touch and hearing. Eye movements were monitored for 21 of the participants.

Apparatus and Materials. These were exactly as in Experiment 1 .

Design. The blocks alternated between targets expected on the same side (either left or right) for both audition and touch, and targets expected on different sides for each modality (i.e., audition on the left, touch on the right, or vice versa). Twenty-one of the participants started with a same-side block, whereas the remainder began with a different-sides block. The specific expected side for targets in each modality changed across blocks (i.e., the first participant started with the expected target side on the left for the first block, the second participant started with it on the right, etc.) and was counterbalanced within each participant's experimental session. There were two blocks of 48 practice trials, followed by eight blocks of 96 experimental trials.

Procedure. This was similar to that of the previous experiment, with the following exceptions. Targets appeared on the expected side for each modality on $83 \%$ of the trials within a block and on the unexpected side for that modality on the remaining $17 \%$ of the trials. For half of the blocks, at the start of the block a common side was specified verbally as most likely for each modality (i.e., both auditory and tactile targets were more likely on the right, or both were more likely on the left). For the remaining blocks, opposite sides were specif ied as more likely for the two modalities (i.e., auditory targets were more likely on the left and tactile targets on the right, or vice versa). Each modality was equally likely to be more probable toward the left or toward the right of the participant across blocks, for both same-side and different-sides blocks.

At the beginning of each block of trials the participants were verbally instructed to direct their tactile and auditory attention in specific directions throughout the block, while maintaining central fixation. In the same-side blocks, the instruction was to concentrate both their "tactile" and "auditory" attention on the single specified side on which targets were more likely for both modalities, whereas in the different-sides blocks the participants were instructed to attend audition on one particular side and to attend touch on the opposite side, in accordance with the target probabilities for that block. These instructions were equally valid for both auditory and tactile targets and on both same-side and different-sides blocks. In all cases, $83 \%$ of the targets were on the specified side for that modality, with only $17 \%$ of the trials contradicting the expectation. Note that the expectations concerning target side should not bias the up-down choice response, as target elevation was equally unpredictable in all cases.

\section{Results}

Fewer than $14 \%$ of the trials were removed due to excessive eye movements (or blink artifacts), and fewer than $1.5 \%$ were removed overall due to no response made within $1,500 \mathrm{msec}$ of target onset. The interparticipant mean RTs (after these exclusions), together with the corresponding error rates for all trials, and the mean spatial expectancy effects are shown in Table 2 as a function of block type, target modality, spatial expectancy, and whether or not eye position was monitored. The mean expectancy effects are also summarized in Figure 3 , pooled across the eye-monitoring factor.

The data were analyzed using a mixed ANOVA, with the between-participants factor of eye monitoring (2) and three within-participants factors [block type (2: same-side vs. different-sides) $\times$ target modality (2: auditory vs. tactile) $\times$ spatial expectancy (2)]. The analysis of the RT data revealed that the participants responded more rapidly to targets appearing on the expected side $(M=611 \mathrm{msec})$ than to those appearing on the unexpected side $(M=659 \mathrm{msec})$ overall, resulting in a main effect of spatial expectancy $[F(1,40)=127.1, p<.001]$. There was also a significant main effect of block type $[F(1,40)=$ $6.7, p=.01]$ caused by the participants' responding significantly more rapidly to targets in the different-sides blocks $(M=630 \mathrm{msec})$ than to targets in the same-side blocks $(M=640 \mathrm{msec})$. We discuss this finding, which also occurred in Experiment 3, after that experiment. The interaction between block type and spatial expectancy was significant $[F(1,40)=20.6, p<.001]$, showing that spatial expectancy effects were significantly greater for the same-side blocks (mean expectancy effect of $59 \mathrm{msec}$, $p<.001$ by $t$ test $)$ than for the different-sides blocks $(M=$ $36 \mathrm{msec}, p<.001)$, in contradiction of the modalityspecific resource account. The participants responded more rapidly to tactile targets $(M=584 \mathrm{msec})$ than to auditory targets $(M=686 \mathrm{msec})$ overall, leading to a main effect of target modality $[F(1,40)=118.2, p=.001]$. 
Table 2

Mean Reaction Times (RTs, in Milliseconds), Standard Errors, Percentages of Errors (\%), and Mean Expectancy Effects for Auditory and Tactile Targets in Experiment 2 as a Function of Eye Monitoring, Block Type, and Target Side

\begin{tabular}{|c|c|c|c|c|c|c|c|c|c|}
\hline \multirow{3}{*}{$\begin{array}{c}\text { Block } \\
\text { Type }\end{array}$} & \multirow{3}{*}{$\begin{array}{c}\text { Target } \\
\text { Modality }\end{array}$} & \multicolumn{6}{|c|}{ Target Side } & \multirow{2}{*}{\multicolumn{2}{|c|}{$\begin{array}{l}\text { Mean Expectancy } \\
\text { Effect }\end{array}$}} \\
\hline & & \multicolumn{3}{|c|}{ Expected } & \multicolumn{3}{|c|}{ Unexpected } & & \\
\hline & & RT & $S E$ & $\%$ & RT & $S E$ & $\%$ & RT & $\%$ \\
\hline \multicolumn{10}{|c|}{ Eye Movement Not Monitored $(n=21)$} \\
\hline Same side & Auditory & 693 & 23 & 1.7 & 775 & 31 & 21.0 & $82 *$ & $19.3 *$ \\
\hline Different sides & & 688 & 23 & 14.0 & 744 & 29 & 22.0 & $56^{*}$ & $7.0^{*}$ \\
\hline Same side & Tactile & 593 & 19 & 2.5 & 654 & 22 & 13.8 & $61^{*}$ & $11.3^{*}$ \\
\hline Different sides & & 603 & 20 & 1.6 & 621 & 22 & 2.3 & 18 & 0.7 \\
\hline \multicolumn{10}{|c|}{ Eye Movement Monitored $(n=21)$} \\
\hline Same side & Auditory & 621 & 19 & 10.2 & 675 & 21 & 15.6 & $54 *$ & 5.4 \\
\hline Different sides & & 617 & 18 & 9.7 & 673 & 24 & 11.2 & $56 *$ & 1.5 \\
\hline Same side & Tactile & 535 & 14 & 4.8 & 573 & 16 & 1.4 & $38 *$ & -3.4 \\
\hline Different sides & & 538 & 14 & 2.5 & 552 & 14 & 2.5 & 14 & 0 \\
\hline
\end{tabular}

Note- $* p<.00125$. Target side refers to whether the target appeared on the side that was expected for each individual target modality. This strict criterion for significance reflects our use of Bonferroni $t$ test pairwise comparisons to correct for possible family-wise error rates when multiple planned comparisons are performed.

There was also an interaction between target modality and spatial expectancy $[F(1,40)=20.1, p<.001]$, with larger expectancy effects reported for auditory targets $(M=63 \mathrm{msec})$ than for tactile targets $(M=53 \mathrm{msec})$ overall.

There was a main effect of eye monitoring $[F(1,40)=$ $7.3, p=.01]$, with eye-monitored participants responding more rapidly than unmonitored participants overall $(M=$ $598 \mathrm{msec}$ vs. $671 \mathrm{msec}$, respectively). There was also a significant three-way interaction between block type, spatial expectancy, and eye monitoring $[F(1,40)=5.1, p<$ $.05]$, which was attributable to greater spatial expectancy effects reported for same-side blocks (vs. different-sides blocks) in the unmonitored participants ( $M=72 \mathrm{vs}$. $37 \mathrm{msec}$, respectively) than in the eye-monitored participants ( $M=47$ vs. $35 \mathrm{msec}$, respectively). Note that although there was no significant difference in the magnitude of spatial expectancy effects between the same-side and different-sides blocks for the eye-monitored participants in this analysis of the RT data, significant differences between these block types were revealed in the analysis of the error data (see below). There was no interaction between eye monitoring and spatial expectancy $[F(1,40)=2.6, p=.11$, although mean expectancy effects were numerically somewhat larger for the unmonitored group (54 msec) than for the eye-monitored group $(41 \mathrm{msec})]$ nor for any of the other terms involving the eye-monitoring factor [for block type $\times$ eye monitoring, $F(1,40)=1.3, p=.26$; for block type $\times$ target modality $\times$ eye monitoring, $F(1,40)=1.3, p=.26 ; F<1$ for all other terms involving the eye-monitoring factor]. Therefore, any expectancy effects cannot be accounted for in terms of overt orienting toward the expected side, since clear spatial effects were found within both the eye-monitored and -unmonitored participants. When averaged over the eye-monitoring factor (see Figure 3), the mean expectancy effects were significant for both modalities in both the same-side and different-sides blocks (all $p$ s $<.01$, including the $16 \mathrm{msec}$ effect for tactile stimuli in the differentsides blocks). Finally, there was a borderline significant interaction between target modality, spatial expectancy, and block type $[F(1,40)=3.8, p=.06]$, reflecting the fact that the largest expectancy effects were reported for auditory targets in the same-side blocks and the smallest were reported for tactile targets in the different-sides blocks (see Figure 3 ). None of the other terms in the analysis of the RT data reached significance $(F<1$ for all other terms).

A similar analysis of the error data revealed a main effect of target modality $[F(1,40)=74.2, p<.001]$ caused

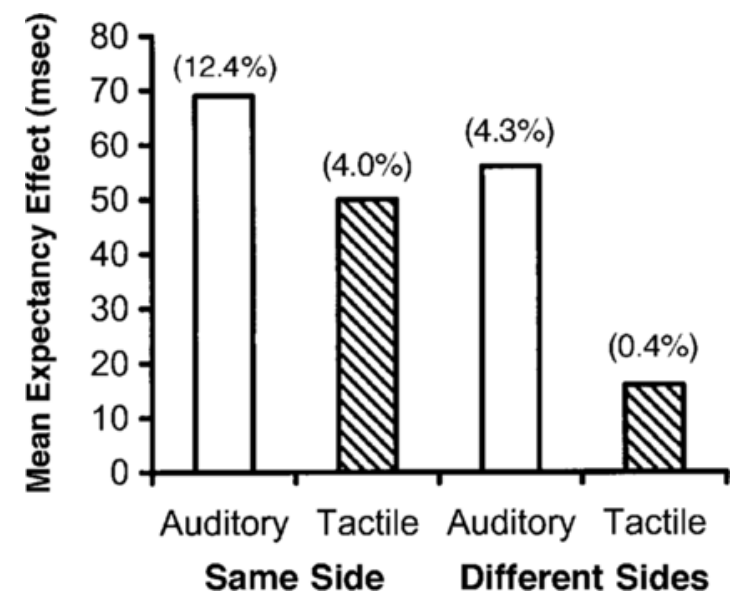

Figure 3. Mean spatial expectancy effects on reaction time, averaged across the eye-monitoring factor, for same-side and different-sides blocks in Experiment 2. White bars show effects for auditory targets, striped bars those for tactile targets. Average expectancy effects in error rate are shown in parentheses. 
by the participants' making more errors in response to auditory targets $(M=13.2 \%)$ than to tactile targets $(M=$ $3.9 \%)$ overall, as in Experiment 1 . The main effect of spatial expectancy also reached significance $[F(1,40)=$ $46.1, p<.001]$, reflecting the fact that the participants made more errors on the unexpected $(M=11.2 \%)$ than on the expected $(M=5.9 \%)$ target side. Spatial expectancy effects were larger for the same-side blocks (mean difference in percentage of errors between unexpected and expected trials $=8.1 \%$ ), than for the differentsides blocks (mean difference $=2.5 \%$ ), resulting in an interaction between block type and spatial expectancy $[F(1,40)=18.5, p<.001]$. Both the main effect of the eye-monitoring factor $[F(1,40)=3.1, p=.08]$ and its interaction with block type $[F(1,40)=3.7, p=.06]$ approached significance, which is attributable to the fact that the eye-monitored participants made fewer errors on different-sides blocks than did the unmonitored participants ( $M=6.5 \%$ and $10.0 \%$, respectively), whereas there was less difference between the groups for the same-side blocks ( $M=8.0 \%$ and $9.8 \%$, respectively). There was also a significant four-way interaction $[F(1,40)=5.0$, $p=.03]$, reflecting the fact that the highest proportion of errors was recorded in response to auditory targets presented on the unexpected side in the same-side blocks for the unmonitored participants (see Table 2). There is no obvious explanation for this interaction term, and so it is not discussed further here. None of the other terms in the analysis of the error data reached significance [for block type, $F(1,40)=2.1, p=.16$; for target modality $\times$ spatial expectancy, $F(1,40)=1.2, p=.27 ; F<1$ for all other terms].

The results of Experiment 2 show that spatially separating auditory and tactile attention led to smaller spatial expectancy effects for targets in both modalities: For tactile targets, expectancy effects were reduced in terms of both the response latency data $(M=50 \mathrm{msec}$ on sameside vs. $16 \mathrm{msec}$ on different-sides blocks, $p<.001$, paired-samples $t$ test) and the error data $(M=3.9 \%$ on same-side vs. $0.3 \%$ on different-sides blocks, $p<.05$ ). For auditory targets, mean expectancy effects were significantly reduced in the error data $(M=12.3 \%$ on sameside vs. $4.7 \%$ on different-sides blocks, $p<.001$, pairedsamples $t$ test), but the similar trend in the RT data $[M=$ $69 \mathrm{msec}$ on same-side blocks vs. $56 \mathrm{msec}$ on differentsides blocks; $t(41)=1.43, p=.16$ ] failed to reach statistical significance. Visual inspection of the mean expectancy effects column of Table 2 suggests that the latter trend in the data might reflect the combination of a significant reduction in the spatial expectancy effect for auditory targets in the non-eye-movement monitored participant group (mean reduction of $26 \mathrm{msec}$ ), together with no significant difference for the eye-movement monitored group (mean reduction of $-1 \mathrm{msec}$ ). However, further analysis revealed that this reduction in the spatial expectancy effect still failed to reach significance when just the unmonitored participants were analyzed separately $[t(20)=1.82, p=.08]$, thus supporting the conclusions based on the overall group data. Our results therefore suggest that the cost of dividing attention across different locations is more pronounced for tactile targets than for auditory targets (since this cost was evident in both the RT and the error data for tactile targets, but only in the error data for auditory targets). However, such an interpretation is complicated somewhat by the pattern of results in the error analysis, since the drop in spatial expectancy effects in terms of errors was numerically larger for auditory targets (same-side - differentsides difference of $7.6 \%)$ than for tactile targets $(M=$ $3.6 \%$ ). A subsequent analysis of the data in terms of inverse efficiency, a performance measure that combines RT and error data into a single term (where inverse efficiency equals average response time divided by proportion correct for each condition; see Spence, Kingstone, Shore, \& Gazzaniga, 2001; Townsend \& Ashby, 1983), revealed that this reduction in the magnitude of spatial expectancy effects for the different-sides blocks in comparison with those of the same-side blocks was still significantly greater for tactile targets than for auditory targets $[t(41)=2.7, p=.01]$ when assessed in terms of this combined response measure.

\section{Discussion}

The results of Experiment 2 demonstrate for the first time that people can shift and sustain both their auditory and tactile endogenous spatial attention in the same direction simultaneously, and also that they can direct attention in the two different modalities to opposite sides under suitable conditions (i.e., when the stimulus probabilities and experimenter instructions strongly favor such a division of attention). The finding that significant spatial expectancy effects were reported in both the same-side and different-sides blocks for targets in both modalities is inconsistent with the supramodal attentional hypothesis (see, e.g., Farah et al., 1989; Robin \& Rizzo, 1989), which predicts that people should not be able to direct their auditory and tactile attention to different locations simultaneously. However, the fact that the mean expectancy effects were significantly smaller in the different-sides blocks than in the same-side blocks for both auditory and tactile targets is also inconsistent with the modality-specific resource view of attention (see, e.g., Bushara et al., 1999; Duncan et al., 1997; Wickens, 1980, 1984, 1992). If the attentional systems for the two modalities were independent, the participants should have found it no more difficult (i.e., no less efficient) to direct their attention to different locations in the two modalities than to direct it to the same location.

Instead, the results of Experiment 2 support the view that people find it difficult to "split" their auditory and tactile attention to different sides simultaneously (i.e., that directing auditory and tactile attention to different sides is less efficient than directing it to the same side). These findings are entirely consistent with our previous 
findings regarding the nature of crossmodal links in endogenous spatial attention between the auditory and visual modalities (Spence \& Driver, 1996) and between the visual and tactile modalities (Spence, Pavani, \& Driver, 2000). The results of the first two experiments reported here are compatible with the "separable-but-linked" view of crossmodal links in endogenous spatial attention (Spence \& Driver, 1996). According to this account, there are separate endogenous attentional systems for audition and touch, but there are also some crossmodal links between the modalities that make it difficult to direct attention in the two modalities to different locations, but allow them to be separated, to some extent, under certain conditions (though see also Eimer, 1999, in press).

Given that the results of Experiment 2 show that participants can direct and sustain their auditory and tactile endogenous spatial attention on different sides of space simultaneously, one might wonder why the participants in Experiment 1 did not also direct their attention in the secondary modality to the side opposite that on which their attention was focused in the primary modality (and where targets in the secondary modality were more likely to be). We believe that two factors will have contributed to this result: First, the fact that the targets in the secondary modality were far less likely than those in the primary modality in the previous experiment, and, second, that we explicitly instructed our participants to try to leave their attention in the secondary modality spatially diffuse. We believe that these factors will have given our participants sufficient reason not to attempt to shift their attention in the secondary modality in Experiment 1. Taken together, the results of the first two experiments show that people can shift and sustain their attention in one sensory modality without it having any necessary consequences for attention in the other modality, but that people find it harder to maintain spatial expectancies on different sides in the two modalities in comparison with directing and sustaining them on the same side.

\section{EXPERIMENT 3}

In our final experiment, we investigated whether audiotactile spatial attention operates within a high-level representation of external space that takes account of current posture, as has been suggested previously to explain crossmodal links in attention between vision and touch (see Driver \& Spence, 1998c; Eimer et al., 2001) and between vision and audition (see Spence \& Driver, 1998). According to this account, the limitation on people's ability to attend to stimuli in the different-sides blocks of Experiment 2 depends on whether or not the stimuli in the two modalities are expected in the same location in external space, with it being difficult to maintain spatial expectancies whenever stimuli are expected in different locations in the two modalities (i.e., as in the different-sides blocks of Experiment 2). However, an al- ternative account of the different-sides deficit in Experiment 2 might be that attentional restrictions reflect some low-level fixed-mapping between the senses, such that participants always find it difficult to direct their auditory attention to the left hemifield and their tactile attention to their right hand, irrespective of where the right hand happens to be positioned in external space (see Eimer et al., 2001). Note that a fixed-mapping account cannot simply reflect the initial hemispheric projections of the stimuli in the two modalities (as has been postulated to account for visual-tactile links in endogenous covert spatial attention; see Spence, Pavani, \& Driver, 2000), because free-field auditory stimuli are known to project bilaterally to both cerebral hemispheres (see, e.g., Kelly, 1991).

These two accounts of crossmodal links in spatial attention make very different predictions regarding the effect of crossing the hands on spatial expectancy effects. With the hands crossed, the left hand is coded as being on the same side as the right auditory field, and likewise for the right hand and left auditory field. If attention operates on an internal representation of external space, then changing the posture should have no effect on the pattern of spatial expectancy effects observed (and least when the same side and different sides are coded with respect to the external spatial locations of expected stimuli in each modality). By contrast, if some fixed mapping exists between the senses, the pattern of expectancy effects for same-side and different-sides blocks should be reversed when the hands are crossed (since expecting tactile targets to the left hand and sounds in the right hemifield, which led to small spatial expectancy effects in the different-sides blocks of Experiment 2, would now lead to small expectancy effects in the same-side blocks of Experiment 3, because of the way in which the conditions are coded). Finally, if crossing the hands leads only to a partial remapping of audiotactile space, then an intermediate result would be expected-that is, there would be significant changes in the pattern of spatial expectancy effects from those reported in Experiment 2, but the different-sides blocks would not necessarily lead to larger spatial expectancy effects than the same-side blocks in this experiment.

\section{Method}

Participants. Thirty-eight participants ( 24 women and 14 men) with a mean age of 31 years and a range of 21-54 years, took part in this experiment. All were right-handed by self-report, and none had taken part in either of the preceding experiments. All the participants reported normal touch and hearing. Eye movements were monitored for 19 of the participants.

Apparatus, Materials, Design, and Procedure. These were as in Experiment 2, with the one exception that the participants now crossed their hands throughout each experimental block (see Figure 4). Accordingly, they grasped the right cube between the forefinger and thumb of the left hand, and the left cube between the forefinger and thumb of the right hand, at the same eccentricity as before. As in Experiment 2, at the beginning of each block of trials the participants were verbally instructed to direct their tactile and 


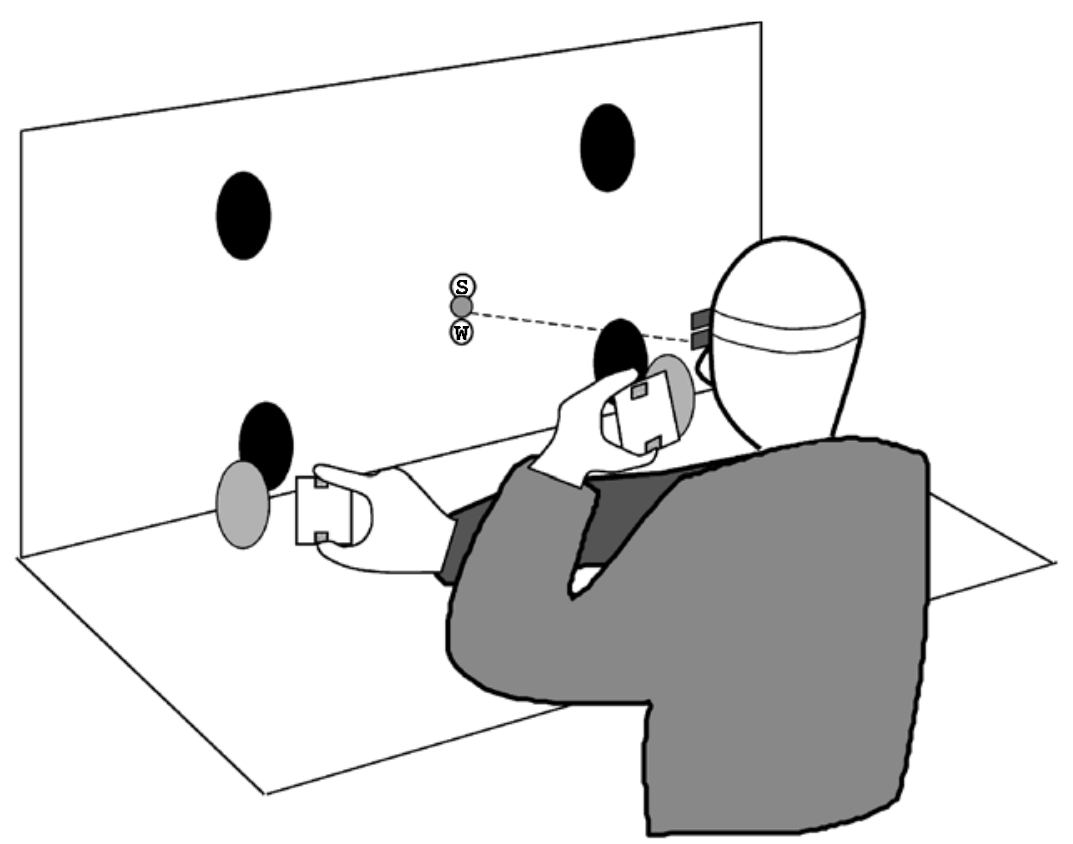

- Fixation Light

Auditory Loudspeakers

Masking Loudspeakers

Figure 4. Schematic view of the apparatus and the participant's position in Experiment 3. The only change in comparison with Experiment 2 (Figure 1) was that the participant's hands were now held in a crossed posture throughout every block of trials.

auditory attention in specif ic external directions (i.e., attend touch on the right side and audition on the left side, or vice versa) throughout the block, because the corresponding target modality was much more likely on a particular side in external space.

\section{Results}

Ten percent of the trials were removed due to excessive eye movements (or blink artifacts) for those participants whose eye movements were monitored, and fewer than $1.3 \%$ of all trials were removed because no response was made within $1,500 \mathrm{msec}$ of target onset. The interparticipant mean RTs (after these exclusions), together with the corresponding error rates for all trials, and the mean spatial expectancy effects are shown in Table 3 as a function of block type, target modality, and expectancy, as a function of the eye-monitoring factor. The mean spatial expectancy effects are also summarized in Figure 5, pooled across the eye-monitoring factor. The data were analyzed using a mixed ANOVA, with the betweenparticipants factor of eye monitoring (2) and three within-participants factors [block type (2: same side vs. different sides) $\times$ target modality (2: auditory vs. tactile) $\times$ spatial expectancy (2)]. Note that in the present analysis, the levels of the block-type factor are considered in terms of the external location from which stimuli were expected (i.e., the same-side blocks comprised targets expected on the left hand and in the right field for audition, or on the right hand and left auditory field, since the hands were now crossed).

The analysis of the RT data revealed a main effect of spatial expectancy $[F(1,36)=84.4, p<.001]$ caused by the participants' responding more rapidly to targets appearing on the expected side $(M=608 \mathrm{msec})$ than to those appearing on the unexpected side $(M=650 \mathrm{msec})$. As in Experiment 2, RTs were faster overall for the differentsides blocks $(M=622 \mathrm{msec})$ than for the same-side blocks $(M=636 \mathrm{msec})$, resulting in a main effect of block type $[F(1,36)=9.4, p=.004]$. There was also an interaction between block type and spatial expectancy $[F(1,36)=4.5, p=.04]$, with larger expectancy effects reported for targets in the same-side blocks $(M=47 \mathrm{msec}$, $p<.01)$ than for targets in the different-sides blocks $(M=$ $36 \mathrm{msec}, p<.001)$. The participants responded more rapidly to tactile targets $(M=597 \mathrm{msec})$ than to auditory targets $(M=675 \mathrm{msec})$ overall, resulting in a main effect of target modality $[F(1,36)=90.9, p<.001]$. The inter- 
Table 3

Mean Reaction Times (RTs, in Milliseconds), Standard Errors, Percentages of Errors (\%), and Mean Expectancy Effects for Auditory and Tactile Targets in Experiment 3 as a Function of Eye Monitoring, Block Type, and Target Side

\begin{tabular}{|c|c|c|c|c|c|c|c|c|c|}
\hline \multirow{3}{*}{$\begin{array}{l}\text { Block } \\
\text { Type }\end{array}$} & \multirow{3}{*}{$\begin{array}{c}\text { Target } \\
\text { Modality }\end{array}$} & \multicolumn{6}{|c|}{ Target Side } & \multirow{2}{*}{\multicolumn{2}{|c|}{$\begin{array}{c}\text { Mean Expectancy } \\
\text { Effect }\end{array}$}} \\
\hline & & \multicolumn{3}{|c|}{ Expected } & \multicolumn{3}{|c|}{ Unexpected } & & \\
\hline & & RT & $S E$ & $\%$ & RT & $S E$ & $\%$ & RT & $\%$ \\
\hline \multicolumn{10}{|c|}{ Eye Movement Not Monitored $(n=19)$} \\
\hline Same side & Auditory & 585 & 24 & 6.8 & 633 & 26 & 11.3 & $48 \dagger$ & 4.5 \\
\hline Different sides & & 588 & 21 & 6.5 & 626 & 26 & 9.5 & $38 \dagger$ & 3.0 \\
\hline Same side & Tactile & 512 & 18 & 1.9 & 558 & 87 & 2.6 & $46 \dagger$ & 0.7 \\
\hline Different sides & & 514 & 16 & 2.1 & 537 & 16 & 2.5 & $23^{*}$ & 0.4 \\
\hline \multicolumn{10}{|c|}{ Eye Movement Monitored $(n=19)$} \\
\hline Same side & Auditory & 726 & 25 & 11.0 & 787 & 32 & 15.9 & $61 *$ & 4.9 \\
\hline Different sides & & 702 & 24 & 12.7 & 756 & 24 & 15.0 & $54 \dagger$ & 2.3 \\
\hline Same side & Tactile & 626 & 17 & 3.0 & 661 & 20 & 2.3 & $35 \dagger$ & -0.7 \\
\hline Different sides & & 612 & 15 & 2.5 & 639 & 20 & 2.8 & $27 *$ & 0.3 \\
\hline
\end{tabular}

$* p<.00625 . \dagger p<.00125$. This strict criterion for significance reflects our use of Bonferroni $t$ test pairwise comparisons to correct for possible family-wise error rates when multiple planned comparisons are performed.

action between target modality and spatial expectancy was also significant $[F(1,36)=8.8, p=.005]$, with larger spatial expectancy effects reported for auditory targets $(M=50 \mathrm{msec}, p<.001)$ than for tactile targets $(M=$ $33 \mathrm{msec}, p<.001$ ), as in the previous experiment.

The analysis of the RT data also revealed a main effect of eye monitoring $[F(1,36)=18.1, p<.001]$, with the unmonitored participants responding more rapidly than the eye-monitored participants $(569$ vs. $689 \mathrm{msec}$, respectively-the opposite pattern to that found in the previous two experiments). The interaction between eye monitoring and block type approached significance $[F(1,36)=3.4, p=.07]$, reflecting the fact that the eyemonitored participants tended to respond more slowly than the unmonitored participants to stimuli in same-side blocks ( $M=700 \mathrm{msec}$ and $572 \mathrm{msec}$, respectively) than in different-sides blocks $(M=677 \mathrm{msec}$ and $566 \mathrm{msec}$, respectively). Note, however, that there were no interactions with eye monitoring involving the critical spatial expectancy factor [for eye monitoring $\times$ spatial expectancy, $F(1,36)<1$, n.s.; for target modality $\times$ eye monitoring, $F(1,36)=2.3, p=.14$; for block type $\times$ target modality $\times$ eye monitoring, $F(1,36)=1.2, p=.28$; for eye monitoring $\times$ target modality $\times$ spatial expectancy, $F(1,36)=2.2, p=.15 ; F<1$ for all other terms involving the eye-monitoring factor]. In fact, spatial expectancy effects were, if anything, numerically larger for the eyemonitored group than for the unmonitored group in both the different-sides $(M=41 \mathrm{msec}$ and $31 \mathrm{msec}$, respectively) and same-side ( $M=48 \mathrm{msec}$ and $47 \mathrm{msec}$, respectively) blocks, showing that they cannot be accounted for in terms of overt orienting. None of the other terms in the RT analysis reached significance $(F<1$ for all other terms).

A similar analysis of the error data revealed a main effect of target modality $[F(1,36)=51.9, p<.001]$ caused by the participants' making more errors in response to auditory targets $(M=11.1 \%)$ than in response to tactile targets $(M=2.5 \%)$ overall, as in the two previous experiments. The interaction between target modality and spatial expectancy was also significant $[F(1,36)=13.1, p=$ $.001]$, revealing a significant spatial expectancy effect for auditory targets $(M=3.7 \%, p<.001)$ but not for tactile targets $(M=0.2 \%$, n.s.; see Figure 5$)$. The main effect of eye monitoring was borderline significant $[F(1,36)=$ $3.6, p=.07]$, as was the interaction between eye monitoring and target modality $[F(1,36)=4.0, p=.054]$, reflecting the fact that the eye-monitored participants tended to make more errors than the unmonitored participants, especially in response to auditory targets $(M=$

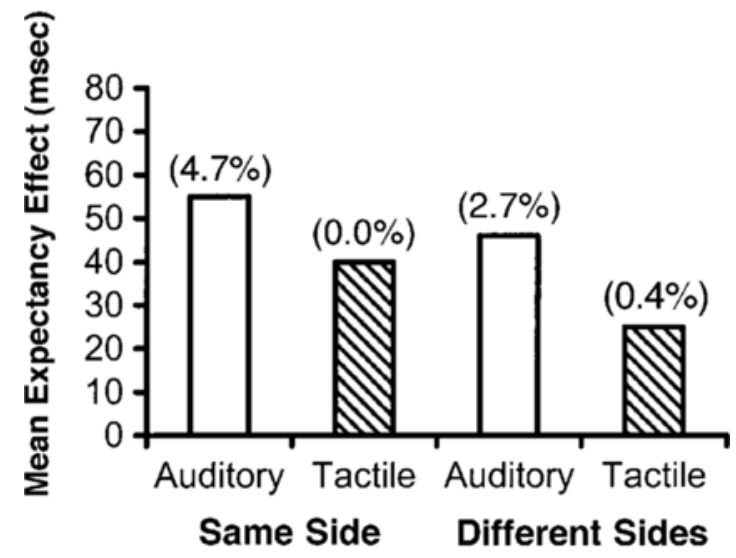

Figure 5. Mean spatial expectancy effects on reaction time, averaged across the eye-monitoring factor, for same-side and different-sides blocks in Experiment 3. "Same side" and "different sides" refer to whether the expected tactile and auditory stimuli appeared on the same side or on different sides of external space. White bars show effects for auditory targets, striped bars those for tactile targets. Average expectancy effects in error rates are shown in parentheses. 
$13.7 \%$ and $8.5 \%$, respectively) in comparison with tactile targets ( $M=2.7 \%$ and $2.3 \%$, respectively). The eyemonitoring factor did not interact with any of the other factors in the error analysis (all $F \mathrm{~s}<1$ ). None of the other terms in the analysis of the error data reached statistical significance [for block type $\times$ spatial expectancy, $F(1,36)=1.1, p=.31$; for block type $\times$ target modality $\times$ spatial expectancy, $F(1,36)=1.5, p=.23 ; F<1$ for all other terms].

\section{Discussion}

Significantly larger spatial expectancy effects were reported for targets in the same-side blocks than for targets in the different-sides blocks, just as in the previous experiment. The similarity of the results across these two experiments (cf. Figures 3 and 5) supports the view that attention operates on a representation of external space that is fully updated (or remapped) as posture changes. ${ }^{2}$ Our results are clearly inconsistent with the fixed-mapping account of crossmodal links in audiotactile attention, which predicted a reversal of the same-side and differentsides expectancy effects when the hands were crossed. In a related study, Eimer et al. (2001) also found that if endogenous tactile spatial attention was shifted to either the left or the right hand when the hands were crossed over the midline, then auditory attention would follow to the same (correct) external location, as demonstrated by an enhanced negativity overlapping with the $\mathrm{N} 1$ component for irrelevant auditory stimuli (presented by the attended as opposed to the unattended hand), as well as enhanced negativities beyond $200 \mathrm{msec}$. Eimer et al.'s (2001) findings therefore provide converging ERP evidence for a remapping of audiotactile space when the hands are crossed over the midline. The present results go beyond Eimer et al.'s (2001) findings by highlighting for the first time the behavioral consequences of such crossmodal links in spatial attention when posture changes.

Another interesting result to emerge from the analyses of both Experiments 2 and 3 was that response latencies were slower overall in the same-side blocks than in the different-sides blocks. Given that the magnitude of spatial expectancy effects was actually significantly larger in the same-side blocks than in the different-sides blocks, these findings suggest that spatial expectancy effects may reflect the consequences of the inhibition of responses to stimuli at unexpected locations, rather than the facilitation of responses to stimuli at the cued (or expected) location. A very similar pattern of results was also reported in our previous studies of crossmodal links in endogenous spatial attention (Spence \& Driver, 1996; Spence, Pavani, $\&$ Driver, 2000, Spence, Shore, \& Klein, 2001), as well as in a number of other unimodal studies of spatial attention (e.g., Dai, Scharf, \& Buus, 1991; Gawryszewski, Riggio, Rizzolatti, \& Umiltà, 1987; Shiu \& Pashler, 1994).

One final potentially interesting finding to emerge from the analysis of the results of Experiment 3 was the significant main effect of eye monitoring, reflecting the fact that the eye-monitored participants responded more slowly overall than did the unmonitored participants. This pattern of results is the reverse of that reported in the first two experiments, in which the eye-monitored participants actually responded significantly more rapidly than did the unmonitored participants. It seems likely that these between-groups differences may simply reflect differences in the overall motivation/arousal levels of the participants we happened to test in each of the eye-monitoring groups, rather than a fundamental difference in behavior as a function of whether or not eye position was monitored. What is perhaps more important for present purposes (in particular with relation to ruling out an overt orienting account of our spatial expectancy effects) is that although there were some trends toward differences in the magnitude of spatial expectancy effects between the two participant groups in the various experiments, these effects never reached statistical significance and, also, differed between different experiments. So, for example, whereas spatial expectancy effects were numerically somewhat larger for the unmonitored group than for the eye-monitored group in Experiment $2(M=$ 54 vs. $41 \mathrm{msec}$, respectively), the reverse trend was apparent for Experiment 3 ( $M=39$ vs. $45 \mathrm{msec}$, respectively). When all of these results are taken together, it would appear that no simple account of our spatial expectancy effects can be put forward on the basis of whether or not the participants' eye position was monitored. The only trend would seem to be that participants who responded more slowly overall were likely to show somewhat larger spatial expectancy effects. Nevertheless, given that other researchers have, on occasion, also found significant differences in attentional effects between eye-monitored and -unmonitored participants (e.g., Jordan, Patching, \& Milner, 1998; Spence \& Driver, 1997a), this is an area that may warrant further consideration in future research.

\section{GENERAL DISCUSSION}

The three experiments reported here were designed to examine the nature of any crossmodal links in sustained endogenous covert spatial attention between audition and touch. In Experiment 1, we demonstrated that when the participants had a strong spatial expectancy about target location in one modality (the more common primary modality), their endogenous spatial attention shifted to that side only within the primary modality and not within the less common secondary modality. This result suggests some degree of independence between auditory and tactile spatial attention and contrasts with the strong crossmodal links in endogenous spatial attention reported previously both between audition and vision (e.g., Driver \& Spence, 1994; Spence \& Driver, 1996) and between vision and touch (Spence et al., 1998; Spence, Pavani, \& Driver, 2000). For example, in a design almost identical to that used in Experiment 1, Spence and Driver (1996) demonstrated that an endogenous shift of either 
auditory or visual attention leads to a concomitant shift of attention in the other modality in the same direction (albeit at a reduced level). Similar crossmodal links in attention have been demonstrated between vision and touch as well (Spence, Pavani, \& Driver, 2000). A comparison of the attentional effects across all three of these behavioral studies (see Figure 6) highlights the fact that crossmodal links in endogenous spatial attention appear to be stronger between vision and the other sensory modalities (i.e., either audition or touch) than between audition and touch.

Experiment 2 provided a further test of any crossmodal links between audition and touch by examining whether people can direct and sustain their endogenous spatial attention on different sides in audition and touch when the event probabilities within both modalities strongly encouraged such a "splitting" of attention. The results showed that people found it significantly easier to sustain their auditory and tactile attention on the same side than on different sides, which supports the existence of some obligatory crossmodal links in endogenous spatial attention between audition and touch. Once again, these results can be compared with previous results concerning audiovisual (Spence \& Driver, 1996, Experiment 7; see also Eimer, 1999) and visuotactile links in endogenous spatial attention (Spence, Pavani, \& Driver, 2000, Experiment 5) using the same orthogonal-cuing paradigm (see Figure 7). The most important comparison for present purposes is that between the attentional effects seen for the different-sides versus same-side blocks for each pair of modalities. This provides a measure of the strength of any obligatory crossmodal links in attention, with large decreases in expectancy effects in different-sides blocks suggesting the existence of strong crossmodal links (such that it is hard to maintain spatial expectancies in different locations for the different modalities), and small decreases suggesting relatively weak crossmodal links. Visual inspection of Figure 7 clearly

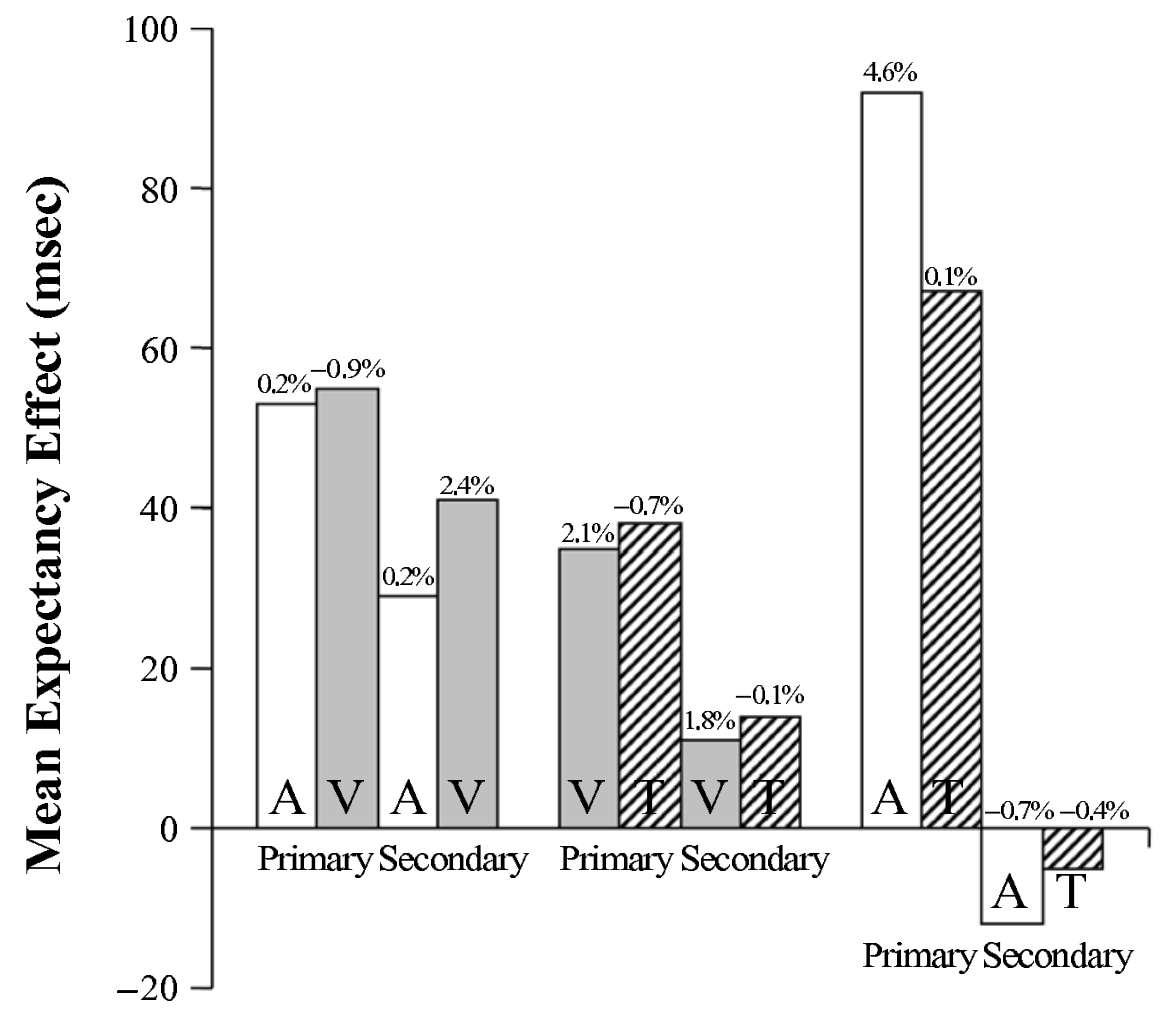

\section{Audiovisual Visuotactile Audiotactile}

Figure 6. Mean spatial expectancy effects on reaction time (RT) for auditory (white bars), visual (gray bars), and tactile (striped bars) target trials as a function of the primary/secondary modality manipulation. Average expectancy effects in error rates are shown above the associated RT effects. Audiovisual data are from Spence and Driver (1996, Experiments 4 and 5), visuotactile data are from Spence, Pavani, and Driver (2000, Experiment 4), and audiotactile data are from our Experiment 1 . The same orthogonal-cuing methodology was used in all the experiments, although, as has already been noted in the text, the signal-to-noise ratios of the various target stimuli were not matched, and, in contrast to the present study, the target stimuli were actually presented from the same two possible target positions in Spence and Driver's (1996) and Spence, Pavani, and Driver's previous studies. 


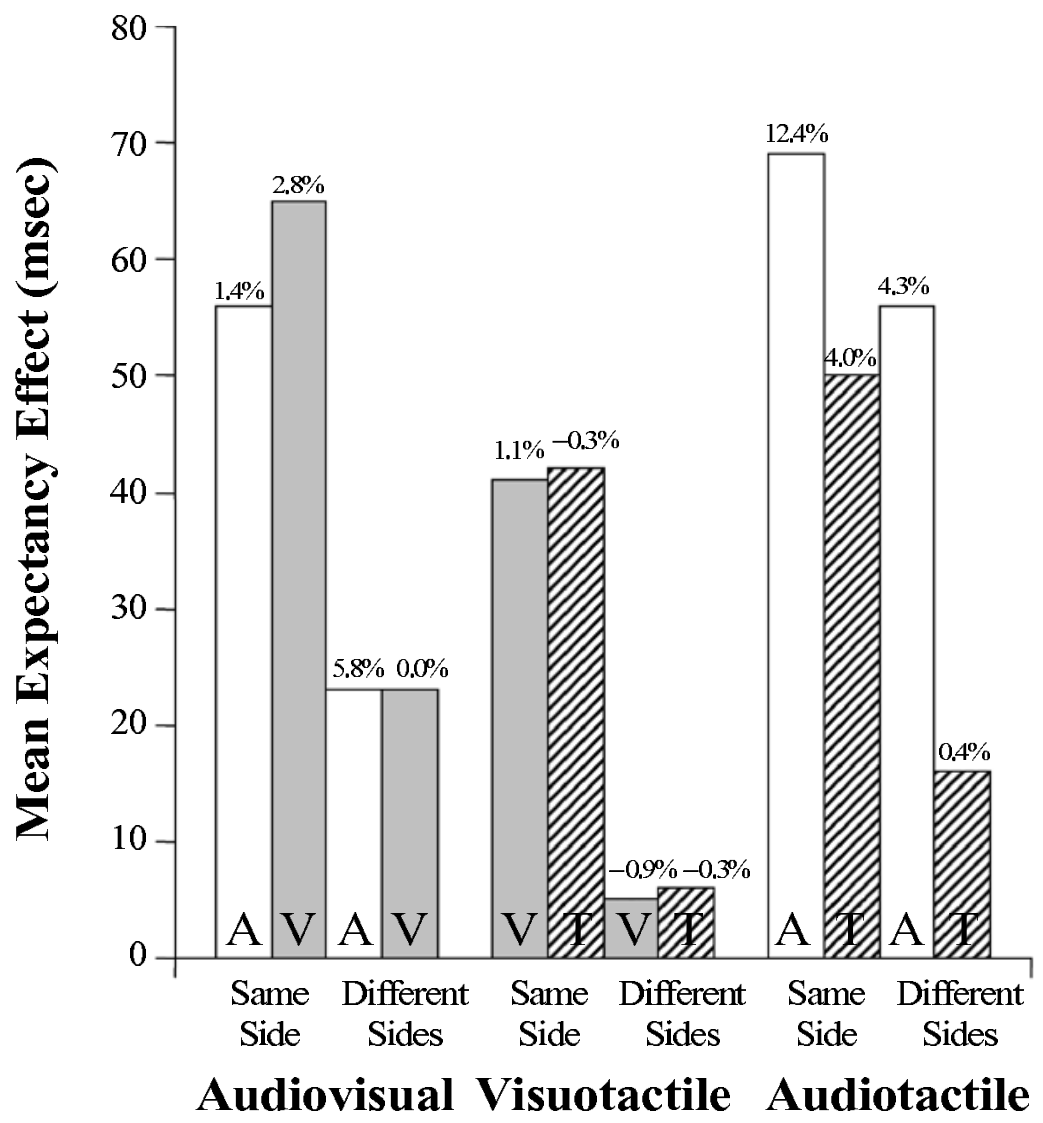

Figure 7. Mean spatial expectancy effects on reaction time (RT) for auditory (white bars), visual (gray bars), and tactile (striped bars) target trials, as a function of the same-side/different-sides attentional manipulation. Average expectancy effects in error rates are shown above the associated RT effects. Audiovisual data are from Spence and Driver (1996, Experiment 7), visuotactile data are from Spence, Pavani, and Driver (2000, Experiment 5), and audiotactile data are from our Experiment 2. All experiments used the same orthogonal-cuing methodology. Note that the signalto-noise ratios of the various target stimuli were not matched, and, in contrast to the present study, the target stimuli were actually presented from the same two possible target positions in Spence and Driver's (1996) and Spence, Pavani, and Driver's previous studies.

shows that people find it difficult to maintain spatial expectancies in different positions for different modalities, no matter which pair of sensory modalities is tested.

In the final experiment, we investigated whether crossmodal attentional links operate within multimodal spatial representations that code for the current position of stimuli in external space (Driver \& Spence, 1998c; Spence \& Driver, in press), or whether, instead, they reflect some kind of fixed mapping between the various sensory modalities. We attempted to distinguish between these two accounts by introducing a crossed-hands posture manipulation (see also Eimer et al., 2001; Kennett et al., 2001; Kennett, Spence, \& Driver, 2002; Spence, Pavani, \& Driver, 2000, for similar experimental manipulations for assessing the nature of any visuotactile links in spatial attention). Spatial expectancy effects for same- side blocks were once again significantly greater than those for the different-sides blocks, as they had been in Experiment 2. This pattern of results is more consistent with the remapping account, which predicts that the pattern of expectancy effects in Experiments 2 and 3 should have been very similar, than with the fixed-mapping account, which instead predicts a complete reversal of spatial expectancy effects for the same-side and different-sides blocks. We are aware of only one previous behavioral study that has compared the uncrossed and crossed postures to address issues concerning the spatial coding responsible for auditory stimulus-response compatibility effects, such as the Simon effect (Simon, Hinrichs \& Craft, 1970). However, mere stimulus-response compatibility cannot explain our effects, because we always ensured that not only the required discrimination (up-down) 
but also the required responses (with the foot pedals) was orthogonal to the lateral direction of attention that produced the critical attentional effects. Our results are consistent with the near-perfect remapping of visuotactile space reported in crossed-hands studies of crossmodal links of both endogenous and exogenous covert orienting using the same orthogonal-cuingparadigm as that reported here (e.g., Kennett et al., 2001; Spence et al., 1998; Spence, Pavani, \& Driver, 2000). Taken together, these results suggest that the multisensory representation of space is fully updated when the hands are crossed, so that endogenous spatial attention is directed to the same (i.e., correct) external location to facilitate the processing of any sensory stimuli (no matter what their modality) that might be presented there.

ERP studies have also been used to demonstrate crossmodal links in spatial attention between audition and vision (e.g., Eimer \& Schröger, 1998; Hillyard et al., 1984; Teder-Sälejärvi et al., 1999), vision and touch (Eimer et al., 2001; Eimer \& Driver, 2000), and, more recently, between audition and touch as well (Eimer et al., 2001; Eimer et al., 2002; Hötting et al., 2002). Although none of the latter audiotactile ERP studies provided any behavioral evidence regarding the consequences of crossmodal links in spatial attention between audition and touch, they did provide the first empirical evidence of any links between this particular pairing of sensory modalities. What's more, Eimer et al. (2001) also reported converging ERP evidence for a remapping of audiotactile space when the hands were crossed over the midline. Endogenous auditory spatial attention was shown to shift toward the correct external location of the hand on which tactile attention was focused, no matter whether the hands were uncrossed or crossed over the midline, just as in the present experiment.

It should be noted that the results reported here concern the sustained deployment of spatial attention to particular locations in specific sensory modalities. A similar sustained attention design was also used by Eimer et al. (2002) and by Hötting et al. (2002) in their ERP studies. In our own behavioral work, we have typically chosen to investigate crossmodal links in endogenous spatial attention using sustained attention designs (as embodied by the block-by-block cuing technique). This is because sustained attention designs appear to lead to more robust spatial expectancy effects than when transient endogenous attention was investigated (i.e., as indexed by trial-by-trial cuing paradigms; but see Posner, Snyder, \& Davidson, 1980, for contradictory results). We have found this especially noticeable when participants are instructed to try and direct their spatial attention in opposite directions in different modalities, as in the different-sides blocks of Experiments 2 and 3 (see Spence \& Driver, 1996, Experiments 6 and 7, for empirical evidence on this point). A comparison of the recent audiotactile ERP studies provides some evidence regarding possible differences between the sustained and transient forms of attentional orienting. In Eimer et al.'s (2001) study, attention was directed to one or other side on a trial-by-trial basis, by means of an informative central arrow cue, rather than on a block-by-block basis, as in Hötting et al.'s study. Whereas Hötting et al. found that a sustained shift of attention in either modality elicited a small but significant shift of attention in the other modality, Eimer et al. (2001) found that although auditory ERPs were affected by a transient shift of tactile attention to one side or the other, there were no such consequences of a transient shift of auditory attention on ERPs to tactile stimuli. Given that some researchers of intramodal visual and auditory selective attention have also reported that sustained and transient attention can affect ERPs differently (e.g., Eimer, 1996, 1998; Schröger, 1993; Schröger \& Eimer, 1993), these results raise further questions about the optional versus obligatory nature of the links in endogenous spatial attention between audition and touch. It remains an interesting question for future research to determine whether behavioral links in crossmodal spatial attention are the same for the case of transient shifts of spatial attention as for the case of sustained attention, as reported here.

The existence of crossmodal links between audition and touch demonstrated behaviorally in the present series of experiments and electrophysiologically by Eimer et al. (2001; Eimer et al., 2002) and Hötting et al. (2002) is inconsistent with both the purely supramodal account of attention (e.g., Farah et al., 1989; Robin \& Rizzo, 1989) and a purely modality-specific attentional resource account (e.g., Bushara et al., 1999; Duncan et al., 1997; Wickens, $1980,1984,1992)$. Instead, the present results are more consistent with the "separable-but-linked" account of crossmodal links in endogenous attention proposed by Spence and Driver (1996; Spence, Pavani, \& Driver, 2000) to account for both audiovisual and visuotactile links in endogenous covert spatial attention. According to the "separable-but-linked" account, there are separable systems for audition and touch, but spatial synergies exist between them. As a result, covert attention can be more efficiently applied to the same location (as in the sameside blocks of Experiment 2) than to different locations in the two modalities (as in the different-sides blocks of Experiment 2). However, these crossmodal links are sufficiently weak that auditory or tactile attention can be directed in a particular direction while attention in the other modality is left spatially diffuse (Experiment 1).

The question remains as to why audiotactile links in endogenous spatial attention should be weaker than those reported previously for other pairs of sensory modalities. One factor that might help to explain these differences relates to the relative positioning of target stimuli in each modality. In our previous studies of audiovisual and visuotactile endogenous covert spatial attention, the target stimuli were always presented from exactly the same possible positions in each modality [e.g., from loudspeakers placed above and below fixa- 
tion and from LEDs placed directly in front of the loudspeakers (Spence \& Driver, 1996), or from vibrators placed next to the thumb and index fingers and from lights placed directly next to the vibrators (Spence, Pavani, \& Driver, 2000)]. By contrast, in the present study, due to limitations in peoples' ability to discriminate the elevation of auditory stimuli (see Spence \& Driver, 1994), auditory and tactile targets were presented from very different possible target positions: The tactile stimulators (both upper and lower) were presented close to the lower target loudspeakers, whereas the upper target loudspeakers were situated by themselves (see Figures 1 and 4). Given that crossmodal attentional effects are strongest when stimuli in different modalities are presented from exactly the same spatial position (cf. Spence, 2001; Spence \& Driver, 1998; Ward et al., 1998; but see also Ward, Prime, \& McDonald, 2002), we thought it possible that any crossmodal links in spatial attention in the present experiment might be less apparent for the upper auditory targets than for lower auditory targets (because both the upper and lower tactile stimuli were presented from close to the lower loudspeaker cones). In order to test this possibility, we reanalyzed the data from all three experiments, including the additional factor of target elevation (upper vs. lower target position; see the Appendix). Whereas these analyses revealed somewhat larger spatial expectancy effects for lower targets than for upper targets in Experiments 2 and 3, these differences were no larger for auditory targets than for tactile targets. This result argues against a spatial artifact account of why the crossmodal links in sustained endogenous spatial attention between audition and touch should be weaker than those between other pairs of modalities (since this would have predicted that smaller expectancy effects should have been reported just for upper auditory targets, which were displaced from all of the other target stimuli). Nevertheless, it will be important in future studies of crossmodal links in audiotactile attention to consider the use of other tasks, such as the implicit spatial discrimination task (e.g., McDonald \& Ward, 1999), to ensure that the target stimuli are presented from exactly the same spatial locations on either side of fixation, while the spatial component of the task is retained (see also Ward et al., 2002, on the issue of paradigm convergence).

Neurophysiological considerations provide an alternative account for the weaker crossmodal links in endogenous spatial attention between audition and touch. In particular, research has highlighted the existence of bimodal cells in the brain that respond to both auditory and tactile/somatosensory stimuli in a number of brain structures, including the superior colliculus (SC; Huerta \& Harting, 1984; Stein \& Meredith, 1993), ventral premotor cortex (Graziano et al., 1997), parietotemporal cortex (Di et al., 1994), and auditory association cortex (Schroeder, Lindsley, Specht, Marcovici, Smiley, \& Javitt, 2001). Crucially, the proportion of auditory-tactile bimodal cells in certain structures, such as the intermediate layers of the SC (a subcortical structure involved in the control of orienting and/or attentive behaviors; see Rizzolatti, Riggio, \& Sheliga, 1994; Spence \& Driver, 1997a; Stein \& Meredith, 1993), is substantially lower (3\% of all cells in the cat SC) than that of either auditory-visual (30\%) or visual-somatosensory (tactile) cells (14\%). Trimodally responsive cells are also poorly represented at $7 \%$ (see Stein \& Meredith, 1993). To the extent that covert spatial attentional effects can be linked to this subcortical structure, one could argue that the relative paucity of audiotactile cells in this or in some other attention-related brain structure(s) may also help to explain the behavioral results seen here (Stein \& Meredith, 1993). ${ }^{3}$

It is also worth considering here Stein and Meredith's (1993) further suggestion that the reason for the paucity of audiotactile bimodal cells may be that audiotactile interactions play more of a functional role in early development (that is, prior to the maturation of the visual system) than in later life. This may be related to the fact that whereas touch primarily informs us about events in near space (and is involved in such things as feeding, grooming, reproduction, and locomotion), audition is primarily a distal sense (although there are some occasions when sound is relevant for near space, as for informing us about an insect that has landed on our back). By contrast, vision informs us about both near and far space. It would clearly be advantageous, then, for audition and vision (i.e., the two distal senses) to be linked, and strong audiovisual links have, in fact, been shown to be crucial for the calibration (and domination) of auditory space (see Bertelson \& de Gelder, in press, and King, in press, for recent reviews). Similarly, the two senses that provide the greatest information about proximal space (e.g., vision and touch) should also presumably be linked for the coordination of manual action (see, e.g., Graziano \& Gross, 1996, 1998; Graziano, Gross, Taylor, \& Moore, in press), and for the calibration of touch in early development. However, it is not so clear what functional purpose would be served by the integration of the primarily distal auditory sense with the proximal tactile sense. These evolutionary considerations might, therefore, also help to explain why audiotactile multisensory interactions may be less pronounced than they are for other pairings of modalities. ${ }^{4}$ Whatever the reason(s) ultimately turn out to be, the point remains that further investigation of the nature of the crossmodal links in endogenous spatial attention (both transient and sustained) between audition and touch, and their comparison with the links between other pairs of modalities, clearly represents an interesting as well as an important area for future research.

\section{REFERENCES}

Bertelson, P., \& DE Gelder, B. (in press). The psychology of multimodal perception. In C. Spence \& J. Driver (Eds.), Crossmodal space and crossmodal attention. Oxford: Oxford University Press.

BRIAND, K. A. (1998). Feature integration and spatial attention: More evidence of a dissociation between endogenous and exogenous ori- 
enting. Journal of Experimental Psychology: Human Perception \& Performance, 24, 1243-1256.

Bushara, K. O., Weeks, R. A., Ishit, K., Catalan, M.-J., Tian, B., Rauschecker, J. P., \& Hallett, M. (1999). Modality-specific frontal and parietal areas for auditory and visual spatial localization in humans. Nature Neuroscience, 2, 759-765.

Butter, C. M. (1987). Varieties of attention and disturbances of attention: A neuropsychological analysis. In M. Jeannerod (Ed.), Neurophysiological and neuropsychological aspects of spatial neglect (pp. 1-23). Amsterdam: Elsevier, North-Holland.

Butter, C. M., Butchel, H. A., \& SAntucci, R. (1989). Spatial attentional shifts: Further evidence for the role of polysensory mechanisms using visual and tactile stimuli. Neuropsychologia, 27, 12311240.

Caclin, A., Soto-Faraco, S., Kingstone, A., \& Spence, C. (2002). Tactile "capture" of audition. Perception \& Psychophysics, 64, 616-630.

Calvert, G. A., Brammer, M. J., \& Iversen, S. D. (1998). Crossmodal identification. Trends in Cognitive Sciences, 2, 247-253.

DAI, H., SchARF, B., \& BuUs, S. (1991). Effective attenuation of signals in noise under focused attention. Journal of the Acoustical Society of America, 98, 798-806.

Di, S., Brett, B., \& BARTh, D. S. (1994). Polysensory evoked potentials in rat parietotemporal cortex: Combined auditory and somatosensory responses. Brain Research, 642, 267-280.

di Pellegrino, G., Làdavas, E., \& Farné, A. (1997). Seeing where your hands are. Nature, $\mathbf{3 8 8 ,} 730$.

DRIVER, J., \& SPENCE, C. J. (1994). Spatial synergies between auditory and visual attention. In C. Umiltà \& M. Moscovitch (Eds.), Attention and performance $X V$ : Conscious and nonconscious processing (pp. 311-331). Cambridge, MA: MIT Press.

Driver, J., \& Spence, C. [J.] (1998a). Attention and the crossmodal construction of space. Trends in Cognitive Sciences, 2, 254-262.

Driver, J., \& Spence, C. [J.] (1998b). Crossmodal attention. Current Opinion in Neurobiology, 8, 245-253.

Driver, J., \& SPEnce, C. [J.] (1998c). Crossmodal links in spatial attention. Philosophical Transactions of the Royal Society of London: Series $B, 353,1319-1331$.

DunCAN, J. (1980). The demonstration of capacity limitation. Cognitive Psychology, 12, 75-96.

Duncan, J., Martens, S., \& Ward, R. (1997). Restricted attentional capacity within but not between sensory modalities. Nature, $\mathbf{3 8 7}$, 808-810.

EIMER, M. (1996). ERP modulations indicate the selective processing of visual stimuli as a result of transient and sustained spatial attention. Psychophysiology, 33, 13-21.

EIMER, M. (1998). Mechanisms of visuospatial attention: Evidence from event-related brain potentials. Visual Cognition, 5, 257-286.

EIMER, M. (1999). Can attention be directed to opposite directions in different modalities? An ERP study. Clinical Neurophysiology, 110, 1252-1259.

EIMER, M. (in press). Electrophysiology of human crossmodal spatial attention. In C. Spence \& J. Driver (Eds.), Crossmodal space and crossmodal attention. Oxford: Oxford University Press.

Eimer, M., Cockburn, D., Smedley, B., \& Driver, J. (2001). Crossmodal links in endogenous spatial attention are mediated by common external locations: Evidence from event-related brain potentials. Experimental Brain Research, 139, 398-411.

Eimer, M., \& Driver, J. (2000). An event-related brain potential study of cross-modal links in spatial attention between vision and touch. Psychophysiology, 37, 697-705.

EIMER, M., \& SCHRÖGER, E. (1998). ERP effects of intermodal attention and cross-modal links in spatial attention. Psychophysiology, 35, 313-327.

Eimer, M., Van Velzen, J., \& Driver, J. (2002). Crossmodal interactions between audition, touch and vision in endogenous spatial attention: ERP evidence on preparatory states and sensory modulations. Journal of Cognitive Neuroscience, 14, 254-271.

Farah, M. J., Wong, A. B., Monheit, M. A., \& Morrow, L. A. (1989). Parietal lobe mechanisms of spatial attention: Modality-specific or supramodal? Neuropsychologia, 27, 461-470.

Foxe, J. J., Morocz, I. A., Murray, M. M., Higgins, B. A., Javitt, D. C.,
\& Schroeder, C. E. (2000). Multisensory auditory-somatosensory interactions in early cortical processing revealed by high-density electrical mapping. Cognitive Brain Research, 10, 77-83.

Gawryszewski, L. DE G., Riggio, L., Rizzolatti, G., \& Umiltà, C. (1987). Movements of attention in the three spatial dimensions and the meaning of "neutral" cues. Neuropsychologia, 25, 19-29.

Graziano, M. S. A., \& Gross, C. G. (1996). Multiple pathways for processing visual space. In T. Inui \& J. L. McClelland (Eds.), Attention and performance XVI: Information integration in perception and communication (pp. 181-207). Cambridge, MA: MIT Press.

Graziano, M. S. A., \& Gross, C. G. (1998). Spatial maps for the control of movement. Current Opinion in Neurobiology, 8, 195-201.

Graziano, M. S. A., Gross, C. G., Taylor, C. S. R., \& Moore, T. (in press). A system of multimodal areas in the primate brain. In C. Spence \& J. Driver, Crossmodal space and crossmodal attention. Oxford: Oxford University Press.

Graziano, M. S. A., Hu, X. T., \& Gross, C. G. (1997). Coding the locations of objects in the dark. Science, 277, 239-241.

Guest, S., Catmur, C., Lloyd, D., \& Spence, C. (2002). Audiotactile interactions in roughness perception. Experimental Brain Research, 146, 161-171.

Hillyard, S. A., Simpson, G. V., Woods, D. L., Van Voorhis, S., \& MÜNTE, T. F. (1984). Event-related brain potentials and selective attention to different modalities. In F. Reinoso-Suarez \& C. AjmoneMarson (Eds.), Cortical integration (pp. 395-414). New York: Raven.

Hötting, K., Rösler, F., \& RöDER, B. (2002). Crossmodal and intermodal attention modulates event-related brain potentials to tactile and auditory stimuli. Experimental Brain Research, 148, 26-37.

Huerta, M. F., \& HARTING, J. K. (1984). The mammalian superior colliculus: Studies of its morphology and connections. In H. Vanagas (Ed.), Comparative neurology of the optic tectum (pp. 687-769). New York: Plenum.

JoNIDES, J. (1981). Voluntary versus automatic control over the mind's eye's movement. In J. Long \& A. Baddeley (Eds.), Attention and performance (Vol. 9, pp. 187-203). Hillsdale, NJ: Erlbaum.

Jordan, T. R., Patching, G. R., \& Milner, D. A. (1998). Central fixations are inadequately controlled by instructions alone: Implications for studying cerebral asymmetry. Quarterly Journal of Experimental Psychology, 51A, 371-391.

JOUSMÄKI, V., \& HARI, R. (1998). Parchment-skin illusion: Sound-biased touch. Current Biology, 8, 869-872.

Kelly, J. P. (1991). Hearing. In E. R. Kandel, J. H. Schwartz, \& T. M. Jessell (Eds.), Principles of neural science (3rd ed., pp. 481-511). Amsterdam: Elsevier.

Kennett, S., Eimer, M., Spence, C., \& Driver, J. (2001). Tactile-visual links in exogenous spatial attention under different postures: Convergent evidence from psychophysics and ERPs. Journal of Cognitive Neuroscience, 13, 462-478.

Kennett, S., Spence, C., \& Driver, J. (2002). Visuo-tactile links in covert exogenous spatial attention remap across changes in unseen hand posture. Perception \& Psychophysics, 64, 1083-1094.

KING, A. (in press). Development of multisensory spatial integration. In C. Spence \& J. Driver (Eds.), Crossmodal space and crossmodal attention. Oxford: Oxford University Press.

KLeIN, R. M., \& Shore, D. I. (2000). Relationships among modes of visual orienting. In S. Monsell \& J. Driver (Eds.), Control of cognitive processes: Attention and performance XVIII (pp. 195-208). Cambridge, MA: MIT Press.

LÀDAVAS, E. (1993). Spatial dimensions of automatic and voluntary orienting components of attention. In I. H. Robinson \& J. C. Marshall (Eds.), Unilateral neglect: Clinical and experimental studies (pp. 193209). East Hove, U.K.: Erlbaum.

Làdavas, E., Pavani, F., \& Farnè, A. (2001). Auditory peripersonal space in humans: A case of auditory-tactile extinction. Neurocase, 7 , 97-103.

Macaluso, E., Frith, C. D., \& Driver, J. (2001). A reply to J. J. McDonald, W. A. Teder-Sälejärvi, \& L. M. Ward: Multisensory integration and crossmodal attention effects in the human brain. Science, 292, 1791.

Mattingley, J. B., Driver, J., Beschin, N., \& Robertson, I. H. (1997). Attentional competition between modalities: Extinction between 
touch and vision after right hemisphere damage. Neuropsychologia, 35, 867-880.

McDonald, J. J., Teder-Sälejärvi, W. A., Heraldez, D., \& HillYARD, S. A. (2001). Electrophysiological evidence for the "missing link" in crossmodal attention. Canadian Journal of Experimental Psychology, 55, 141-149.

McDonald, J. J., Teder-SÄlejërvi, W. A., \& Hillyard, S. A. (2000). Involuntary orienting to sound improves visual perception. Nature, 407, 906-908.

McDonald, J. J., \& WARD, L. M. (1999). Spatial relevance determines facilitatory and inhibitory effects of auditory covert spatial orienting. Journal of Experimental Psychology: Human Perception \& Performance, 25, 1234-1252.

McDonald, J. J., \& WARD, L. M. (2000a). Involuntary listening aids seeing: Evidence from human electrophysiology. Psychological Science, 11, 167-171.

McDonald, J. J., \& WARD, L. M. (2000b). On the modality specificity of stimulus-driven spatial attention orienting and inhibition of return. Unpublished manuscript.

Merat, N., Spence, C., Lloyd, D. M., Withington, D. J., \& MCGLONE, F. (1999). Audiotactile links in focused and divided spatial attention. Society for Neuroscience Abstracts, 25, 1417.

Meredith, M. A., Wallace, M. T., \& Stein, B. E. (1992). Visual, auditory and somatosensory convergence in output neurons of the cat superior colliculus: Multisensory properties of the tecto-reticulospinal projection. Experimental Brain Research, 88, 181-186.

Miller, J. O. (1988). A warning about median reaction time. Journal of Experimental Psychology: Human Perception \& Performance, 14, 539-543.

Mondor, T. A., \& Amirault, K. J. (1998). Effect of same- and differentmodality spatial cues on auditory and visual target identification. Journal of Experimental Psychology: Human Perception \& Performance, 24, 745-755.

Müller, H. J., \& Rabbitt, P. M. A. (1989). Reflexive and voluntary orienting of visual attention: Time course of activation and resistance to interruption. Journal of Experimental Psychology: Human Perception \& Performance, 15, 315-330.

Pavani, F., Spence, C., \& Driver, J. (2000). Visual capture of touch: Out-of-the-body experiences with rubber gloves. Psychological Science, 11, 353-359.

Posner, M. I. (1978). Chronometric explorations of mind. Hillsdale, NJ: Erlbaum.

Posner, M. I., Nissen, M. J., \& Klein, R. M. (1976). Visual dominance: An information-processing account of its origins and significance. Psychological Review, 83, 157-171.

Posner, M. I., Nissen, M. J., \& Ogden, W. C. (1978). Attended and unattended processing modes: The role of set for spatial location. In H. I. Pick \& I. J. Saltzman (Eds.), Modes of perceiving and processing information (pp. 137-157). Hillsdale, NJ: Erlbaum.

Posner, M. I., SNyder, C. R. \& DAVIDSon, B. J. (1980). Attention and the detection of signals. Journal of Experimental Psychology, 2, 160174.

Rafal, R, HeniK, A., \& Smith, J. (1991). Extrageniculate contributions to reflex visual orienting in normal humans: A temporal hemifield advantage. Journal of Cognitive Neuroscience, 3, 322-328.

Rizzolatti, G., Riggio, L., \& Sheliga, B. M. (1994). Space and selective attention. In C. Umiltà \& M. Moscovitch (Eds.), Attention and performance: Conscious and nonconscious information processing (Vol. 15, pp. 231-265). Cambridge, MA: MIT Press.

Robin, D. A., \& Rizzo, M. (1989). The effect of focal cerebral lesions on intramodal and cross-modal orienting of attention. In T. E. Prescott (Ed.), Clinical aphasiology (Vol. 18, pp. 61-74). Boston: CollegeHill.

Schroeder, C. E., Lindsley, R. W., Specht, C., Marcovici, A., SmiLEY, J. F., \& JAVITT, D. C. (2001). Somatosensory input to auditory association cortex in the macaque monkey. Journal of Neurophysiology, 85, 1322-1327.

SCHRÖGER, E. (1993). Event-related potentials to auditory stimuli following transient shifts of spatial attention in a go/nogo task. Biological Psychology, 36, 183-207.
Schröger, E., \& Eimer, M. (1993). Effects of transient spatial attention on auditory event-related potentials. NeuroReport, 4, 588-590.

Shiu, L.-P., \& PAshler, H. (1994). Negligible effect of spatial precuing on identification of single digits. Journal of Experimental Psychology: Human Perception \& Performance, 20, 1037-1054.

Simon, J. R., Hinrichs, J. V., \& Craft, J. L. (1970). Auditory S-R compatibility: Reaction time as a function of ear-hand correspondence and ear-response location correspondence. Journal of Experimental Psychology, 86, 97-102.

Spence, C. [J.] (2001). Crossmodal attentional capture: A controversy resolved? In C. Folk \& B. Gibson (Eds.), Attention, distraction and action: Multiple perspectives on attentional capture (pp. 231-262). Amsterdam: Elsevier.

SPEnCE, C. J., \& Driver, J. (1994). Covert spatial orienting in audition: Exogenous and endogenous mechanisms facilitate sound localization. Journal of Experimental Psychology: Human Perception \& Performance, 20, 555-574.

SPENCE, C. [J.], \& Driver, J. (1996). Audiovisual links in endogenous covert spatial attention. Journal of Experimental Psychology: Human Perception \& Performance, 22, 1005-1030.

SPence, C. [J.], \& Driver, J. (1997a). Audiovisual links in exogenous covert spatial orienting. Perception \& Psychophysics, 59, 1-22.

Spence, C. [J.], \& Driver, J. (1997b). Cross-modal links in attention between audition, vision, and touch: Implications for interface design. International Journal of Cognitive Ergonomics, 1, 351-373.

Spence, C. [J.], \& Driver, J. (1997c). On measuring selective attention to an expected sensory modality. Perception \& Psychophysics, 59, 389-403.

Spence, C. [J.], \& Driver, J. (1998). Crossmodal links between auditory and visual attention. In P. K. Kuhl \& L. A. Crum (Eds.), Proceedings of the 16th International Congress on Acoustics and the 135th Meeting of the Acoustical Society of America (Vol. 3, pp. 15691570). New York: Acoustical Society of America.

SPence, C. [J.], \& Driver, J. (Eds.) (in press). Crossmodal space and crossmodal attention. Oxford: Oxford University Press.

Spence, C. [J.], Kingstone, A., Shore, D. I., \& Gazzaniga, M. S. (2001). Representation of visuotactile space in the split brain. Psychological Science, 12, 90-93.

Spence, C. [J.], Nicholls, M. E. R., Gillespie, N., \& Driver, J. (1998). Cross-modal links in exogenous covert spatial orienting between touch, audition and vision. Perception \& Psychophysics, 60, 544-557.

Spence, C. [J.], Pavani, F., \& Driver, J. (2000). Crossmodal links between vision and touch in covert endogenous spatial attention. Journal of Experimental Psychology: Human Perception \& Performance, 26, 1298-1319.

Spence, C. [J.], Ranson, J., \& Driver, J. (2000). Cross-modal selective attention: On the difficulty of ignoring sounds at the locus of visual attention. Perception \& Psychophysics, 62, 410-424.

Spence, C. [J.], Shore, D. I., \& Klein, R. M. (2001). Multisensory prior entry. Journal of Experimental Psychology: General, 130, 799832.

Stein, B. E., \& Meredith, M. A. (1993). The merging of the senses. Cambridge, MA: MIT Press.

Teder-SälejÄrvi, W. A., Münte, T. F., Sperlich, F.-J., \& Hillyard, S. A. (1999). Intra-modal and cross-modal spatial attention to auditory and visual stimuli: An event-related brain potential (ERP) study. Cognitive Brain Research, 8, 327-343.

Townsend, J. T., \& Ashby, F. G. (1983). Stochastic modelling of elementary psychological processes. New York: Cambridge University Press.

WARD, L. M. (1994). Supramodal and modality-specific mechanisms for stimulus-driven shifts of auditory and visual attention. Canadian Journal of Experimental Psychology, 48, 242-259.

Ward, L. M., McDonald, J. J., \& Golestani, N. (1998). Cross-modal control of attention shifts. In R. Wright (Ed.), Visual attention (pp. 232-268). New York: Oxford University Press.

WARD, L. M., McDonald, J. J., \& Lin, D. (2000). On asymmetries in cross-modal spatial attention orienting. Perception \& Psychophysics, 62, 1258-1264. 
Ward, L. M., Prime, D. A., \& McDonald, J. J. (2002). Converging operations revisited: The case of attention. Abstracts of the Psychonomic Society, 7, 56.

WiCKENS, C. D. (1980). The structure of attentional resources. In R. S. Nickerson (Ed.), Attention and performance VIII (pp. 239-257). Hillsdale, NJ: Erlbaum.

Wickens, C. D. (1984). Processing resources in attention. In R. Parasuraman \& D. R. Davies (Eds.), Varieties of attention (pp. 63-102). San Diego: Academic Press.

WiCKens, C. D. (1992). Engineering psychology and human performance (2nd ed.). New York: Harper Collins.

\section{NOTES}

1. Given that expectancy effects are calculated with respect to spatial expectancy for the primary modality in Experiment 1, negative expectancy effects here reflect a shift of attention away from the direction expected in the primary modality (which is actually the direction in which the majority of the less likely targets in the secondary modality occur).

2. A between-experiments analysis of the data from Experiments 2 and 3 confirmed that crossing the hands had little effect on the pattern of spatial expectancy effects reported. The combined analysis had all the factors of the original analyses, but also included experiment (2 vs. $3)$ as an additional between-participants factor. The analyses revealed no main effect of experiment in terms of the RT data $[F(1,78)<1$, n.s.] and no interactions involving this term [for experiment $\times$ block type $\times$ spatial expectancy, $F(1,78)=2.3, p=.13$; for experiment $\times$ target modality $\times$ spatial expectancy, $F(1,78)=1.7, p=.20]$. Analysis of the error data revealed a significant main effect of experiment in the error data $[F(1,78)=2.8, p=.01]$ as well as significant interactions between experiment and spatial expectancy $[F(1,78)=8.0 . p=.006]$ and between experiment, spatial expectancy, and target modality $[F(1,78)=$ $8.3, p=.005]$. All of these terms can be accounted for by the fact that the participants made fewer errors in response to tactile targets on the expected side when their hands were crossed than when they were uncrossed. Finally, there was also a significant interaction between experiment, spatial expectancy, and block type $[F(1,78)=6.9, p=.01]$ caused by spatial expectancy effects' being slightly smaller in the differentsides blocks when the participants' hands were crossed $(M=1.5 \%)$ than when their hands were uncrossed $(M=2.5 \%)$. None of the other terms involving experiment reached significance [for experiment $\times$ target modality $\times$ spatial expectancy, $F(1,78)=3.6, p=.06 ; F<1$ for all other terms]. Taken together, the results of these between-experiments analyses are far more consistent with crossmodal links in spatial attention's operating on a representation of space that updates as posture changes, than with the fixed-mapping account.

3. Note, though, that far more extensive audiotactile neural interactions have been reported in certain other brain areas, such as the caudomedial belt region of auditory association cortex (Schroeder et al., 2001).

4. We thank Lawrence Ward and Charlie Schroeder for independently suggesting this intriguing evolutionary argument. 


\section{APPENDIX}

In order to ensure that our participants could perform both the auditory and tactile elevation discrimination tasks with a reasonably high degree of accuracy, we had to present the targets in the two modalities from different elevations in the present series of experiments (see Figures 1 and 4). We thought it possible that this difference in target elevation might account for some of the patterns of expectancy effects seen in our main data analyses. Therefore, we conducted further analyses of the data from Experiments 1-3 to clarify the nature of any effects of target elevation on performance. We repeated the main analyses reported in the text, now including the additional factor of target elevation (upper vs. lower targets). Tables A1-A3 show the mean RTs, their standard errors, and the associated error rates, as a function of target elevation, for Experiments $1-3$, respectively.

Analysis of the data from Experiment 1 revealed a nearly significant main effect of target elevation $[F(1,12)=4.6, p=.06]$, reflecting the fact that the participants responded more rapidly to upper targets $(M=650 \mathrm{msec})$ than to lower targets $(M=$ $686 \mathrm{msec}$ ) overall. The four-way interaction between target elevation, primary modality, spatial expectancy, and eye monitoring was also significant $[F(1,12)=15.2, p<.01]$, which is attributable to the fact that larger expectancy effects were reported in the primary modality for upper targets when eye movements were not monitored than when they were monitored. None of the other interactions involving target elevation was significant [for primary modality $\times$ target modality $\times$ target elevation, $F(1,12)=2.5, p=.15$; for target elevation $\times$ spatial expectancy, $F(1,12)=1.9, p=.19$; for primary modality $\times$ target elevation $\times$ spatial expectancy, $F(1,12)=3.5, p=.09$; for target modality $\times$ target elevation $\times$ spatial expectancy, $F(1,12)=1.2, p=.30$; for primary modality $\times$ target modality $\times$ target elevation $\times$ spatial expectancy, $F(1,12)=1.2, p=$ .29 ; for primary modality $\times$ target modality $\times$ target elevation $\times$ eye monitoring, $F(1,12)=1.0, p=.34$; for target elevation $\times$ spatial expectancy $\times$ eye monitoring, $F(1,12)=3.5, p=$ .09 ; for target modality $\times$ target elevation $\times$ spatial expectancy $\times$ eye monitoring, $F(1,12)=2.1, p=.18 ; F<1$ for all other terms]. A similar ANOVA on the error data revealed no significant terms involving elevation [for target elevation $\times$ spatial expectancy, $F(1,12)=2.3, p=.16$; for target elevation $\times$ eye monitoring, $F(1,12)=2.1, p=.17$; for primary modality $\times$ target modality $\times$ target elevation $\times$ spatial expectancy $\times$ eye monitoring, $F(1,12)=1.4, p=.27 ; F<1$ for all other terms].

Analysis of the RT data from Experiment 2 revealed a main effect of target elevation $[F(1,40)=127.2, p<.001]$ caused by the participants' responding more rapidly to upper targets $(M=$ $584 \mathrm{msec})$ than to lower targets $(M=687 \mathrm{msec})$ overall. The analysis also revealed a significant interaction between target elevation and target modality $[F(1,40)=10.2, p=.003]$, reflecting the fact that upper targets $(M=582 \mathrm{msec})$ were responded to more rapidly than lower targets $(M=701 \mathrm{msec})$ in audition and, to a lesser extent, in touch $(M=585 \mathrm{msec}$ and $673 \mathrm{msec}$, respectively). Target elevation also interacted with spatial expectancy $[F(1,40)=20.4, p<.001]$, with greater expectancy effects reported for lower targets (mean expectancy effect $=63 \mathrm{msec}$ ) than for upper targets (mean expectancy effect $=33 \mathrm{msec}$ ). Finally, whereas the magnitude of spatial expectancy effects in the different-sides blocks was greater for lower targets $(M=58 \mathrm{msec})$ than for upper targets $(M=$ $16 \mathrm{msec})$, no such differences were seen in the same-side blocks ( $M=69$ vs. $66 \mathrm{msec}$, respectively), resulting in a borderline-significant interaction between block type, spatial expectancy, and target elevation $[F(1,40)=3.7, p=.06]$. The three-way interaction between target elevation, target modality, and spatial expectancy was significant $[F(1,40)=8.7, p=$ $.005]$, as was the four-way interaction between target elevation, target modality, spatial expectancy, and eye monitoring $[F(1,40)=6.0, p=.02]$. These terms are attributable to the fact that larger spatial expectancy effects were reported for lower auditory targets in different-sides blocks, a trend that was more pronouncedfor the participants whose eye movements were not monitored. Target elevation did not interact with any of the other factors [for target modality $\times$ target elevation $\times$ eye monitoring, $F(1,40)=1.9, p=.18$; for block type $\times$ target modality $\times$ target elevation $\times$ eye monitoring, $F(1,40)=3.8, p=.06$;

Table A1

Mean Reaction Times (RTs, in Milliseconds), Standard Errors (SEs), Percentages of Errors (\%), and Mean Expectancy Effects for Auditory and Tactile Targets in Experiment 1 as a Function of Target Elevation, Primary Modality, and Target Side

\begin{tabular}{|c|c|c|c|c|c|c|c|c|c|}
\hline \multirow{3}{*}{$\begin{array}{l}\text { Primary } \\
\text { Modality }\end{array}$} & \multirow{3}{*}{$\begin{array}{c}\text { Target } \\
\text { Modality }\end{array}$} & \multicolumn{6}{|c|}{ Target Side } & \multirow{2}{*}{\multicolumn{2}{|c|}{$\begin{array}{c}\text { Mean Expectancy } \\
\text { Effect }\end{array}$}} \\
\hline & & \multicolumn{3}{|c|}{ Expected } & \multicolumn{3}{|c|}{ Unexpected } & & \\
\hline & & RT & $S E$ & $\%$ & RT & $S E$ & $\%$ & RT & $\%$ \\
\hline \multicolumn{10}{|c|}{ Upper Targets } \\
\hline Auditory primary & $\begin{array}{l}\text { Auditory } \\
\text { Tactile }\end{array}$ & $\begin{array}{l}622 \\
625\end{array}$ & $\begin{array}{l}33 \\
32\end{array}$ & $\begin{array}{l}6.3 \\
3.8\end{array}$ & $\begin{array}{l}713 \\
619\end{array}$ & $\begin{array}{l}34 \\
32\end{array}$ & $\begin{array}{r}13.3 \\
3.3\end{array}$ & $\begin{array}{l}91 \dagger \\
-5\end{array}$ & $\begin{array}{l}7 \\
0.5\end{array}$ \\
\hline Touch primary & $\begin{array}{l}\text { Tactile } \\
\text { Auditory }\end{array}$ & $\begin{array}{l}528 \\
747\end{array}$ & $\begin{array}{l}17 \\
54\end{array}$ & $\begin{array}{r}2.3 \\
15.2\end{array}$ & $\begin{array}{l}619 \\
726\end{array}$ & $\begin{array}{l}26 \\
46\end{array}$ & $\begin{array}{r}3.2 \\
13.8\end{array}$ & $\begin{aligned} & 91 \dagger \\
- & 21\end{aligned}$ & $\begin{array}{r}0.9 \\
-1.5\end{array}$ \\
\hline \multicolumn{10}{|c|}{ Lower Targets } \\
\hline Auditory primary & $\begin{array}{l}\text { Auditory } \\
\text { Tactile }\end{array}$ & $\begin{array}{l}654 \\
642\end{array}$ & $\begin{array}{l}24 \\
25\end{array}$ & $\begin{array}{r}10.3 \\
6.6\end{array}$ & $\begin{array}{l}769 \\
649\end{array}$ & $\begin{array}{l}37 \\
22\end{array}$ & $\begin{array}{r}14.1 \\
5.8\end{array}$ & $\begin{array}{c}85^{*} \\
7\end{array}$ & $\begin{array}{r}3.8 \\
-0.7\end{array}$ \\
\hline Touch primary & $\begin{array}{l}\text { Tactile } \\
\text { Auditory }\end{array}$ & $\begin{array}{l}574 \\
783\end{array}$ & $\begin{array}{l}24 \\
29\end{array}$ & $\begin{array}{r}5.7 \\
16.0\end{array}$ & $\begin{array}{l}619 \\
767\end{array}$ & $\begin{array}{l}21 \\
35\end{array}$ & $\begin{array}{r}4.1 \\
13.1\end{array}$ & $\begin{array}{c}45 \dagger \\
-14\end{array}$ & $\begin{array}{r}1.6 \\
-2.9\end{array}$ \\
\hline
\end{tabular}

$* p<.00625 . \quad \dagger p<.00125$. This strict criterion for significance reflects our use of Bonferroni $t$ test pairwise comparisons to correct for possible family-wise error rates when multiple planned comparisons are performed. 


\section{APPENDIX (Continued)}

Table A2

Mean Reaction Times (RTs, in Milliseconds), Standard Errors (SEs), Percentages of Errors (\%), and Mean Expectancy Effects for Auditory and Tactile Targets in Experiment 2 as a Function of Target Elevation, Block Type, and Target Side

\begin{tabular}{|c|c|c|c|c|c|c|c|c|c|}
\hline \multirow{3}{*}{$\begin{array}{c}\text { Block } \\
\text { Type }\end{array}$} & \multirow{3}{*}{$\begin{array}{c}\text { Target } \\
\text { Modality }\end{array}$} & \multicolumn{6}{|c|}{ Target Side } & \multirow{2}{*}{\multicolumn{2}{|c|}{$\begin{array}{c}\text { Mean Expectancy } \\
\text { Effect }\end{array}$}} \\
\hline & & \multicolumn{3}{|c|}{ Expected } & \multicolumn{3}{|c|}{ Unexpected } & & \\
\hline & & RT & $S E$ & $\%$ & RT & $S E$ & $\%$ & RT & $\%$ \\
\hline \multicolumn{10}{|c|}{ Upper Targets } \\
\hline Same side & Auditory & 564 & 13 & 3.4 & 608 & 15 & 1.5 & $44 \dagger$ & -1.9 \\
\hline Different sides & & 575 & 14 & 1.8 & 582 & 15 & 1.9 & 7 & 0.1 \\
\hline Same side & Tactile & 563 & 13 & 3.6 & 619 & 16 & 1.3 & $56 \dagger$ & -2.3 \\
\hline Different sides & & 567 & 14 & 2.3 & 592 & 14 & 2.8 & $25 \dagger$ & 0.5 \\
\hline \multicolumn{10}{|c|}{ Lower Targets } \\
\hline Same side & Auditory & 672 & 17 & 13.4 & 736 & 23 & 21.1 & $64 \dagger$ & $7.7 \dagger$ \\
\hline Different sides & & 657 & 16 & 12.7 & 738 & 21 & 19.4 & $81 \dagger$ & $6.7 *$ \\
\hline Same side & Tactile & 643 & 16 & 11.0 & 717 & 20 & 15.6 & $74 \dagger$ & $4.6^{*}$ \\
\hline Different sides & & 649 & 16 & 11.1 & 684 & 19 & 13.8 & $35 \dagger$ & 2.7 \\
\hline
\end{tabular}

$* p<.00625 . \quad \dagger p<.00125$. This strict criterion for significance reflects our use of Bonferroni $t$ test pairwise comparisons to correct for possible family-wise error rates when multiple planned comparisons are performed.

for block type $\times$ target modality $\times$ target elevation $\times$ spatial expectancy $\times$ eye monitoring, $F(1,40)=2.1, p=.16 ; F<1$ for all other terms]. A similar ANOVA on the error data revealed a significant main effect of elevation $[F(1,40)=82.8, p<.001]$, with more errors being made to lower targets $(M=14.8 \%)$ than to upper targets $(M=2.3 \%)$ overall. There was also a significant interaction between target elevation and target modality $[F(1,40)=4.5, p<.05]$, reflecting the fact that more errors were made to lower targets $(M=16.7 \%)$ than to upper targets $(M=$ $2.2 \%)$ in audition than in touch $(M=13.0 \%$ and $M=2.5 \%$, respectively). Target elevation also interacted with spatial expectancy $[F(1,40)=31.3, p<.001]$, with larger spatial expectancy effects being reported for lower targets $(M=5.4 \%)$ than for upper targets $(M=-0.9 \%)$. Target elevation interacted with eye monitoring in the analysis of the error data $[F(1,40)=6.4$, $p=.02]$, reflecting the fact that the participants made significantly fewer errors to upper targets $(M=8.9 \%)$ than to lower targets $(M=10.9 \%)$ when eye movements were not monitored in comparison with when they were monitored $(p=.03)$. There was also a significant interaction between block type $\times$ target elevation $\times$ spatial expectancy $\times$ eye monitoring $[F(1,40)=$ $4.5, p=.04]$. Target elevation did not interact with any of the other factors [for block type $\times$ target elevation, $F(1,40)=1.2$, $p=.27$; for target modality $\times$ spatial expectancy $\times$ target elevation, $F(1,40)=2.6, p=.12$; for target modality $\times$ target elevation $\times$ eye monitoring, $F(1,40)=1.9, p=.17$; for target elevation $\times$ spatial expectancy $\times$ eye monitoring $F(1,40)=1.5$, $p=.23 ; F<1$ for all other terms].

Analysis of the RT data from Experiment 3 revealed a main effect of target elevation $[F(1,36)=79.9, p=.001]$, with the participants responding more rapidly to upper targets $(M=$ $584 \mathrm{msec})$ than to lower targets $(M=674 \mathrm{msec})$ overall, just as in Experiment 2. Target elevation also interacted with spatial expectancy $[F(1,36)=13.6, p=.001]$, with larger spatial expectancy effects being reported for lower targets $(M=51 \mathrm{msec})$ than for upper targets $(M=32 \mathrm{msec})$. However, target elevation did not interact with any of the other factors [for target modal- ity $\times$ target elevation, $F(1,36)=2.7, p=.11$; for block type $\times$ target elevation $\times$ spatial expectancy, $F(1,36)=1.8, p=.19$; for target modality $\times$ target elevation $\times$ spatial expectancy, $F(1,36)=1.2, p=.28$; for target modality $\times$ eye monitoring, $F(1,36)=1.0, p=.31$; for target modality $\times$ target elevation $\times$ eye monitoring, $F(1,36)=1.6, p=.22 ; F<1$ for all other terms]. A similar ANOVA on the error data also revealed a main effect of target elevation $[F(1,36)=60.2, p<.001]$, with more errors made in response to lower targets $(M=10.8 \%)$ than to upper targets $(M=3.4 \%)$. Target elevation also interacted with spatial expectancy $[F(1,36)=7.3, p=.01]$, with larger expectancy effects for the lower targets $(M=3.3 \%)$ than for upper targets $(M=0.5 \%)$. However, target elevation did not interact with any of the other factors [for target modality $\times$ target elevation, $F(1,36)=2.1, p=.16$; for block type $\times$ target elevation $\times$ eye monitoring, $F(1,36)=1.5, p=.22 ; F<1$ for all other terms].

The general pattern of results from these analyses, including the target elevation factor, can be summarized as suggesting an advantage (i.e., faster responses with fewer errors) for upper targets than for lower targets overall. This main effect of target elevation might be attributable, at least in part, to the fact that the masking white-noise loudspeakers were situated by the lower loudspeakercones (so as to best mask the operation of the vibrotactile stimulators). However, since we have also found a similar pattern of results in our elevation analyses of the data from Spence, Pavani, and Driver's (2000) previous study of crossmodal links in endogenous spatial attention between vision and touch (see the Appendix to that paper), when no such masking loudspeakers were present (see also Spence et al., 2001), it seems probable that this effect is also partially attributable to the participants' finding it easier to lift their toes than their heels from the foot-pedals (upper vs. lower responses, respectively).

Target elevation interacted with spatial expectancy in Experiments 2 and 3, reflecting the fact that spatial expectancy effects were greater (both in terms of the RT and error data) for lower targets than for upper targets. This was actually the $o p$ - 
APPENDIX (Continued)

\section{Table A3}

Mean Reaction Times (RTs, in Milliseconds), Standard Errors (SEs), Percentages of Errors (\%), and Mean Expectancy Effects for Auditory and Tactile Targets in Experiment 3 as a Function of Target Elevation, Block Type, and Target Side

\begin{tabular}{|c|c|c|c|c|c|c|c|c|c|}
\hline \multirow{3}{*}{$\begin{array}{l}\text { Block } \\
\text { Type }\end{array}$} & \multirow{3}{*}{$\begin{array}{c}\text { Target } \\
\text { Modality }\end{array}$} & \multicolumn{6}{|c|}{ Target Side } & \multirow{2}{*}{\multicolumn{2}{|c|}{$\begin{array}{c}\text { Mean Expectancy } \\
\text { Effect }\end{array}$}} \\
\hline & & \multicolumn{3}{|c|}{ Expected } & \multicolumn{3}{|c|}{ Unexpected } & & \\
\hline & & RT & $S E$ & $\%$ & RT & $S E$ & $\%$ & RT & $\%$ \\
\hline \multicolumn{10}{|c|}{ Upper Targets } \\
\hline Same side & Auditory & 571 & 15 & 2.5 & 616 & 18 & 4.0 & $45^{*}$ & 1.5 \\
\hline Different sides & & 569 & 14 & 3.8 & 597 & 19 & 3.8 & $28 *$ & 0 \\
\hline Same side & Tactile & 567 & 16 & 2.9 & 600 & 16 & 3.2 & $33^{*}$ & 0.3 \\
\hline Different sides & & 565 & 14 & 3.3 & 586 & 13 & 3.5 & $21^{*}$ & 0.2 \\
\hline \multicolumn{10}{|c|}{ Lower Targets } \\
\hline Same side & Auditory & 671 & 19 & 9.9 & 723 & 23 & 15.0 & $52 *$ & 5.1 \\
\hline Different sides & & 659 & 18 & 11.1 & 704 & 19 & 13.1 & $45^{*}$ & 2 \\
\hline Same side & Tactile & 636 & 20 & 7.6 & 687 & 25 & 10.7 & $51 *$ & 3.1 \\
\hline Different sides & & 627 & 18 & 8.2 & 683 & 24 & 11.1 & $56^{*}$ & 2.9 \\
\hline
\end{tabular}

${ }^{*} p<.00125$. This strict criterion for significance reflects our use of Bonferroni $t$ test pairwise comparisons to correct for possible family-wise error rates when multiple planned comparisons are performed.

posite pattern of results to those observed in Spence, Pavani, and Driver's (2000) reanalysis of their visuotactile data. The tactile target stimuli in the present study were presented from close to the lower target loudspeakers, whereas the upper loudspeakers were more distant (in terms of elevation) from that target tactile stimuli. The participants may therefore have focused their endogenous spatial attention primarily on the lower stimulus positions, given that all the tactile and half of the auditory targets appeared there. This would provide one plausible account for the greater spatial modulation of expectancy effects for lower rather than for upper targets. Background white noise was also presented from the lower locations, and so the participants may also have found the lower auditory targets harder to discriminate. The participants may therefore have allocated their attention preferentially to regions of space where target stimuli were more likely, and also where target discrimination was more difficult, which explains the somewhat greater spatial expectancy effects reported here for lower targets. Note, though, that there was little evidence for this difference in spatial expectancy effects between the upper and lower target locations' being more pronounced for auditory targets than for tactile targets, as one might have expected. 